\title{
Article \\ Neural Network-Based Prediction: The Case of Reinforced Concrete Members under Simple and Complex Loading
}

\author{
Afaq Ahmad $^{1}\left(\mathbb{D}\right.$, Nikos D. Lagaros $^{2, *}$ (D) and Demetrios M. Cotsovos ${ }^{3}$ \\ 1 Department of Civil Engineering, University of Engineering \& Technology Taxila, Taxila 47050, Pakistan; \\ afaq.ahmad@uettaxila.edu.pk \\ 2 Department of Structural Engineering, Institute of Structural Analysis \& Antiseismic Research, \\ School of Civil Engineering, National Technical University of Athens, 9, Heroon Polytechniou Str., \\ Zografou Campus, GR-15780 Athens, Greece \\ 3 Structural Engineering, Heriot-Watt University, Edinburgh EH14 4AS, UK; D.Cotsovos@hw.ac.uk \\ * Correspondence: nlagaros@central.ntua.gr; Tel.: +30-210-772-2625
}

Citation: Ahmad, A.; Lagaros, N.D.; Cotsovos, D.M. Neural NetworkBased Prediction: The Case of Reinforced Concrete Members under Simple and Complex Loading. Appl. Sci. 2021, 11, 4975. https://doi.org/ 10.3390/app11114975

Academic Editor: Laurent Daudeville

Received: 31 March 2021

Accepted: 26 May 2021

Published: 28 May 2021

Publisher's Note: MDPI stays neutral with regard to jurisdictional claims in published maps and institutional affiliations.

Copyright: $\odot 2021$ by the authors. Licensee MDPI, Basel, Switzerland. This article is an open access article distributed under the terms and conditions of the Creative Commons Attribution (CC BY) license (https:// creativecommons.org/licenses/by/ $4.0 /)$.

\begin{abstract}
The objective of this study is to compare conventional models used for estimating the load carrying capacity of reinforced concrete (RC) members, i.e., Current Design Codes (CDCs), with the method based on different assumptions, i.e., the Compressive Force Path (CFP) method and a non-conventional problem solver, i.e., an Artificial Neural Network (ANN). For this purpose, four different databases with the details of the critical parameters of (i) RC beams in simply supported conditions without transverse steel or stirrups (BWOS) and RC beams in simply supported conditions with transverse steel or stirrups (BWS), (ii) RC columns with cantilever-supported conditions (CWA), (iii) RC T-beams in simply supported conditions without transverse steel or stirrups (TBWOS) and RC T-beams in simply supported conditions with transverse steel or stirrups (TBWS) and (iv) RC flat slabs in simply supported conditions under a punching load (SCS) are developed based on the data from available experimental studies. These databases obtained from the published experimental studies helped us to estimate the member response at the ultimate limit-state (ULS). The results show that the predictions of the CFP and the ANNs often correlate closer to the experimental data as compared to the CDCs.
\end{abstract}

Keywords: RC beam; T-beam; columns; slab; ACI; EC2; CFP; ANN

\section{Introduction}

Over the decades, researchers and engineers have proposed many underlying theories [1-6] and tools $[7,8]$ to accurately predict the structural response of reinforced concrete (RC) members at their ultimate limit state (ULS) by keeping a balance between safe and economical design solutions at the same time. Based on these theories, different Current Design Codes (CDC) [1-6] were established and used around the globe. However, the predictions from these CDC mostly underestimate the member response at ULS [9-13]. All these CDC are based on the truss analogy theory (TA), which is a sectional approach. This TA based on the contribution of the stirrups, the uncracked portion of a concrete member and aggregate interlocking mechanism, for measuring the RC member response at ULS as illustrated in Figure 1. However, this is not true in all cases, as the literature shows that the prediction of these CDCs are mostly underestimated compared to the experimental values. Therefore, another theory named the compressive force path (CFP) [14] based on the new, modified design approach or opposite assumptions of the TA, predict RC member responses very close to their experimental values [9-12]. The CFP based on the member response included the critical region of the member between points of the counter flexural, unlike the sectional approach of the TA, as shown in Figure 1. The supports points are denoted by A, B, and D and vertical upward load is applied on C. 


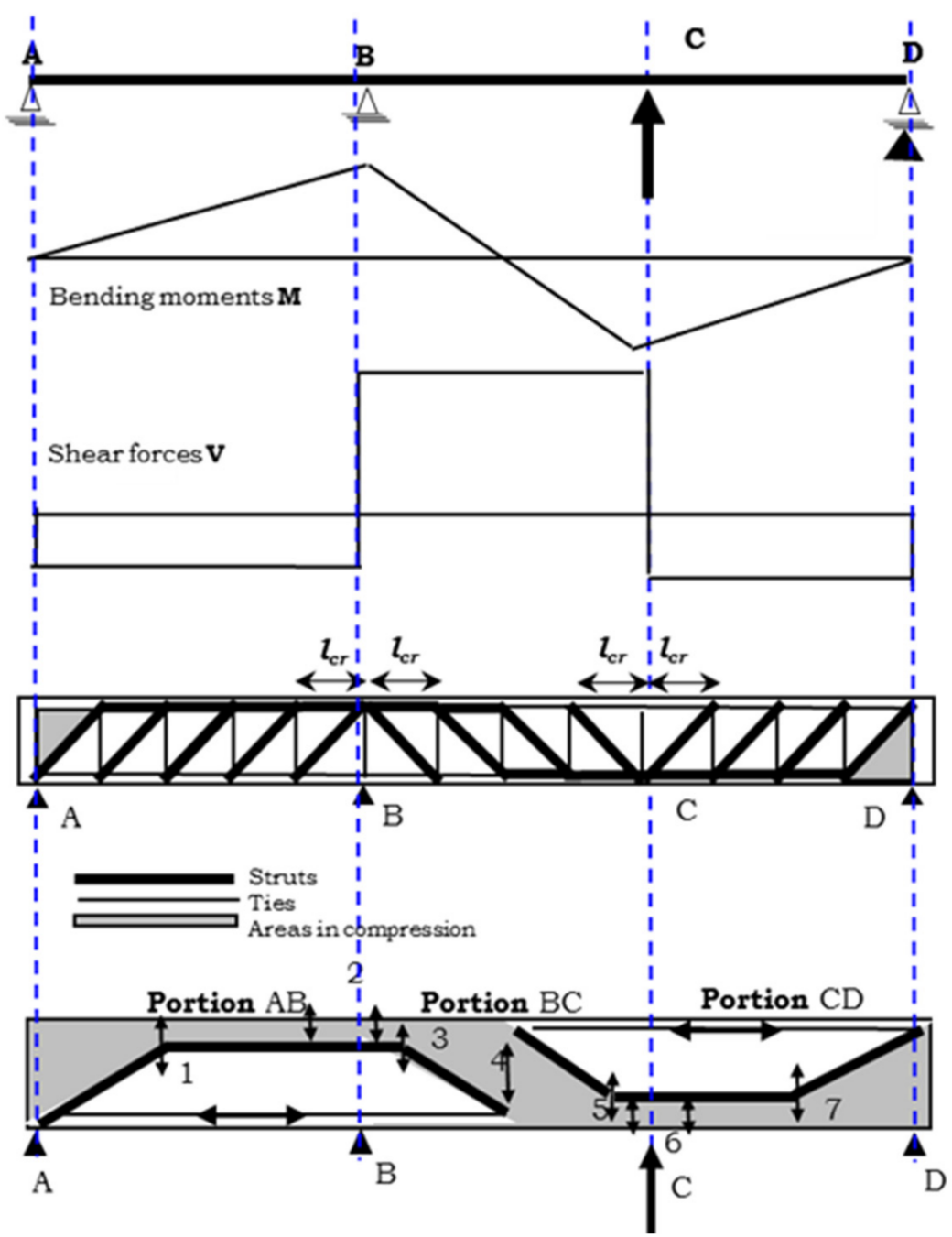

Figure 1. The basic difference of TA and CFP Models [14].

With the computer science advancements in the last two decades, many researchers have proposed the use of soft computing (SC) methods to solve complex problems [15-26]. Artificial neural networks (ANNs), response surface methodology (RSM), fuzzy logic (FL), particle swarm optimization (PSO) and genetic algorithms (GAs) are among the most popular SC methods [27]. In this work to compare the CDC and CFP, an ANN is used to assess the member response of simple and complex RC members at ULS. As previously indicated, ANNs can be used to predict not only the material behavior [28-32], but also the member response $[33,34]$. Furthermore, ANNs are also used to solve different problems associated with analysis domain assessments [35-38], design optimizations [39-41], and especially with reliability assessments [42-45]. Therefore, an ANN is chosen over the other tools in this present work.

In the present work, an effort is done to compare the prediction of CDCs (i.e., $\mathrm{ACI}$ and EC2) [1,2], CFP [14], and ANN for different RC members, i.e., (i) RC beams in simply supported conditions without transverse steel or stirrups (BWOS) and RC beams in simply supported conditions with transverse steel or stirrups (BWS), (ii) RC columns in cantilever supported conditions (CWA), (iii) RC T-beams in simply supported conditions without transverse steel or stirrups (TBWOS) and RC T-beams in simply supported conditions with transverse steel or stirrups (TBWS) and (iv) RC flat slabs in simply supported conditions under a punching load (SCS) at the ULS. For this purpose, four different databases (DB) are developed from the previous experimental studies. The first DB-I is about the simple geometry with simple support conditions, i.e., RC beams in simply supported conditions 
without transverse steel or stirrups (BWOS) and RC beams in simply supported conditions with transverse steel or stirrups (BWS), the second DB-II is about the simple geometry but with cantilever support RC columns (CWA) with fixed support only, the third DB-III is about the complex geometry but in simple support conditions i.e., RC T-beams without transverse steel or stirrups (TBWOS) and T-beams with transverse steel or stirrups (TBWS) in simply supported conditions and the last fourth DB-IV is about the complex geometry with complex loading conditions, i.e., RC flat slab (SCS) under a punching load [13]. The results show that the prediction from the ANNs models for above members correlates closer to the collected experimental data compared to their counterpart CDCs.

\section{Function of Artificial Neural Network (ANN)}

The function of artificial neural networks (ANNs) is inspired by the human biological nervous system [9-13]. ANNs can experience, learn, classify, recognize and predict the assigned problems, based on the information $[46,47]$ fed to them during a training process. ANNs contain a different combination of layers, i.e., input layer, hidden layer(s) and output layer. These layers are interconnected through weighted links, summarized by the activation function, with the free forward and backward calculation phase during the training of the ANN, as illustrated in Figure 2 [9-13]. Equation (1) describe the simplified mathematical function of an artificial neuron:

$$
O=f\left(\sum x_{z} w_{z}+b\right)
$$

where $O$ is the predicted value from ANN, $w_{z}$ are the values of the links, $x_{z}$ are the given assigned input, $b$ are the values of the extra parameter i.e; bias value.

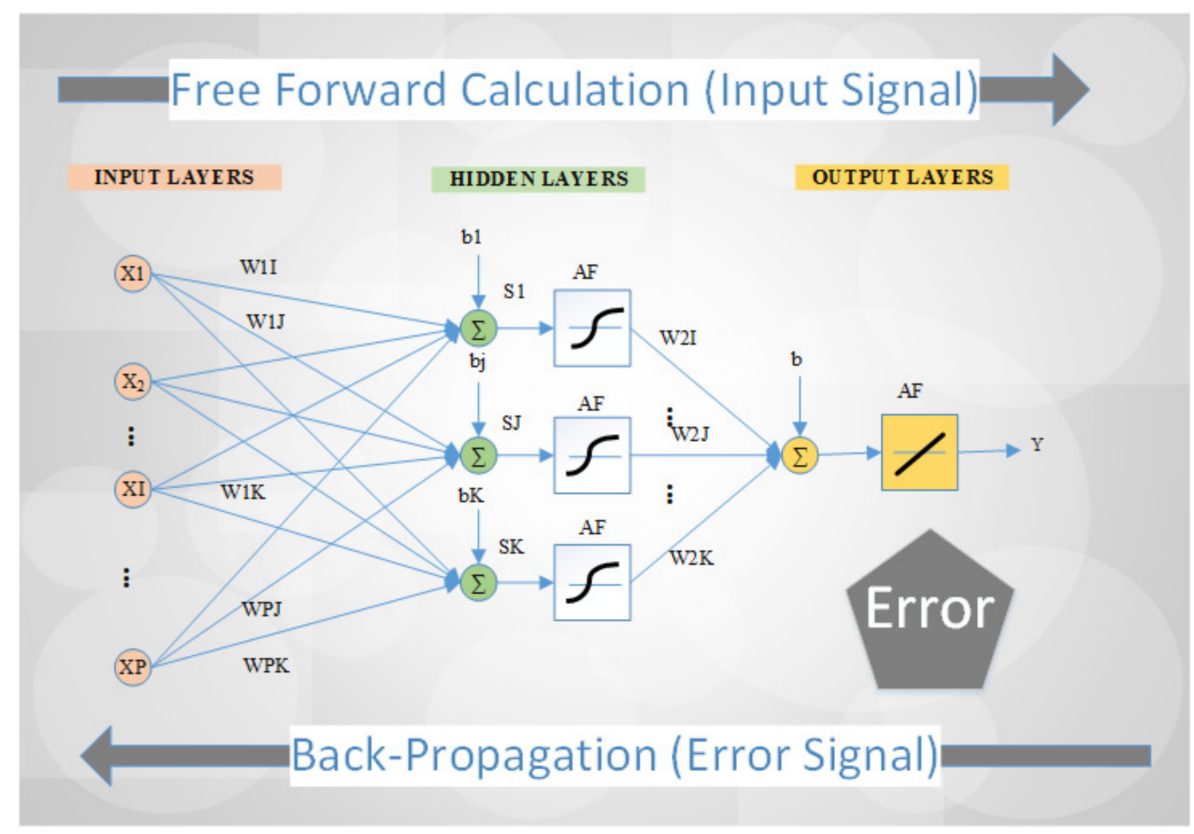

Figure 2. Simplified Mathematical Function of ANN with $\mathrm{X} 1, \mathrm{X} 2 \ldots$ are input, WII, WIJ ... are links, $\mathrm{SI}, \mathrm{SJ} \ldots$ are activation functions and $\mathrm{bI}, \mathrm{bj} \ldots$. are bais values.

The results of the activation task generate the values of the input process of the neurons of the next layer, as shown in Figure 2. The final selected weight values are obtained from the available data training process after giving the first random weights [9-13]. In the present study, ANNs were used to predict the load carrying capacity of the RC members at ULS. Based on experience [9-13], it is considered that multi-layer ANNs (MLFNNs) are more suitable for the type of problem being studied. The formation of ANNs obtained from training defines the number of hidden layers. The signals produced by the neurons move from left to right along the path, as illustrated in Figure 2 [9-13]. Hyperbolic activation 
and activation functions are used in the current study between the input and intermediate layer, and hyperbolic functions are used in the middle and outgoing layer. Equation (2) can determine the error that occurs in this process. After the training of the ANN, the result is then compared to the known target values through the Equation (2).

$$
E(w)=\frac{1}{2} \sum_{i}[T-O]^{2}
$$

where $T$ is the target defined in the database, $O$ is the output value predicted by the ANNs.

The back distribution method or Delta Rule is used to reduce the error found in Equation (2). This recurring search process is performed on the other side, e.g., from right to left of the ANN is shown in Figure 2. Through this process the random weights of the links are adjusted to achieve better accuracy in the output values. This process is repeated until no further improvements are made to the MSE value and errors are acceptable. The ANN process then uses adjusted weights to achieve predictable results with minimal errors.

\subsection{Pre Processing Phase}

The normalization process of the data points has a considerable effect on the ANN training, as through this step, all the different inputs are normalized among the same values regardless of the different units $[48,49]$. Therefore, in this work, all the critical parameters are then normalized between the new limits of 0.1 and 0.9 by using Equation (3):

$$
X=(0.8 / \Delta) x+\left[0.9-(0.8 / \Delta) x_{\max }\right]
$$

where $x$ is the given value, and $X$ is the normalized/uniform value, $\Delta$ is the difference between the two extreme limits.

To make the different combination of the parameters, Pearson's correlation coefficient (r) values are used as defined by Equation (4) [9-13]. If the input parameter has higher values of $|r|$ with respect to the output parameter, then it shows its importance for the output parameter.

$$
r=\frac{n \sum x y-(\Sigma x)(\Sigma y)}{\sqrt{n\left(\Sigma x^{2}\right)-(\Sigma x)^{2}} \sqrt{n\left(\Sigma y^{2}\right)-(\Sigma y)^{2}}}
$$

\subsection{The Features of ANN Model}

The main features for the learning process of the ANN are carried out by the use of multi-layer ANN model coded by the authors in the MATLAB environment by the Levenberg-Marquardt with free forward back-propagation method [50]. The architect of the ANN is used by the outcome of the previous work $[46,47]$. The key features of the training are summarized by as:

- The database is divided by the random method into three sub-sets: $70 \%$ for the training purpose, $15 \%$ for validation purpose and the remaining $15 \%$ for the testing purposes.

- $\quad$ Each ANN models is calibrated for 1000 epochs/cycles.

- The training is stopped if any one of the following conditions is achieved: (a) a maximum of 100 validation failures occur, and (b) the minimum performance learning slope becomes $10^{-8}$.

- The selection of the optimized ANN model is carried by the: (i) The error value of correlation factor (R), (ii) The value of the mean absolute error (MAE) and (iii) the value of the mean squared error (MSE) [51,52] which are analytically expressed by Equations (5)-(7) respectively:

$$
\begin{gathered}
R=\frac{\sum_{i=1}^{n}\left(T_{i}-\bar{T}\right)\left(O_{i}-\bar{O}\right)}{\sum_{1}^{n}\left(T_{i}-\bar{T}\right)^{2} \sum_{1}^{n}\left(O_{i}-\bar{O}\right)^{2}} \\
M S E=\frac{\sum_{i=1}^{n}\left(T_{i}^{2}-O_{i}{ }^{2}\right)}{n}
\end{gathered}
$$




$$
M A E=\frac{\sum_{i=1}^{n}\left|T_{i}-O_{i}\right|}{n}
$$

where $O_{i}$ are the given target values and $T_{i}$ are predicted values from the ANN; $\bar{T}=\sum_{1}^{n} T_{i} / n$ and $\bar{O}=\sum_{1}^{n} O_{i} / n$ are the average of experimental $\left(T_{i}\right)$ and predicted $\left(O_{i}\right)$ values and $n$ is the total number of samples in the databases [9-13]. The ANN model having the highest $R$ values and the lowest MSE and MAE values, can be considered the optimized model [9-13].

\section{Database-I: BWOS and BWS}

The first database (DB-I) contains 619 samples of RC beam specimens without transverse steel or stirrups (BWOS) and 315 samples of RC beam specimens with transverse steel or stirrups (BWS). All these specimens from these two sets were conducted under three or four point loading, as illustrated in Figures 3 and 4. From the BWOS samples, 93\% (i.e., 586) samples failed in a shear manner, and the remaining samples, $8.5 \%$ (i.e., 53 ), failed in a flexural manner. Similarly, from the BWS, $67 \%$ (i.e., 214) samples failed in a shear manner, and the remaining $35 \%$ (i.e., 111) failed in a flexural manner Table 1 provides information about the critical parameters associated with these specimens.

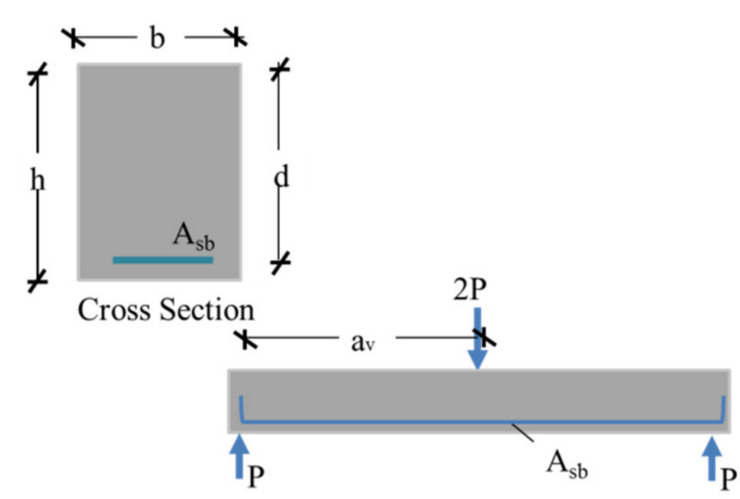

(a)

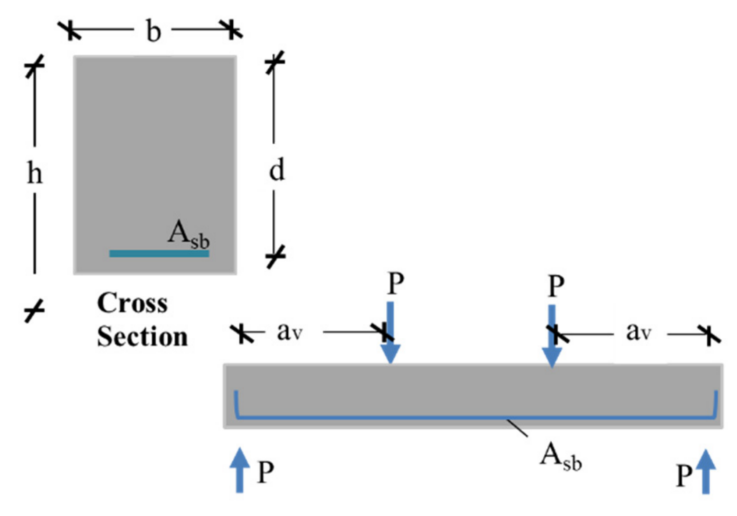

(b)

Figure 3. Simple Loading of (a) Three-point and (b) Four-point Loading for BWOS.

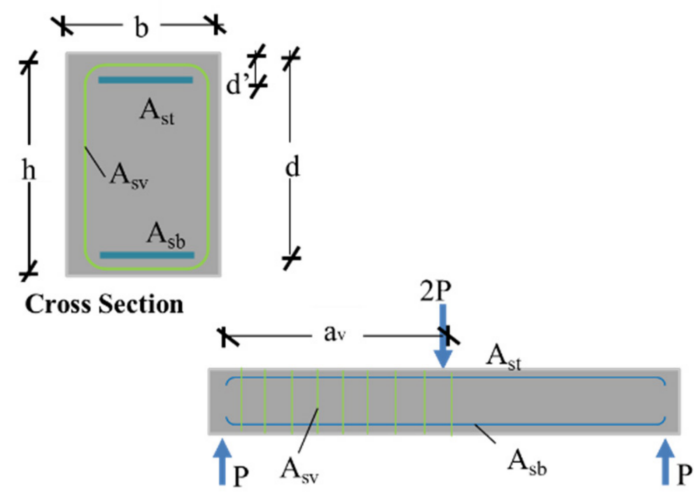

(a)

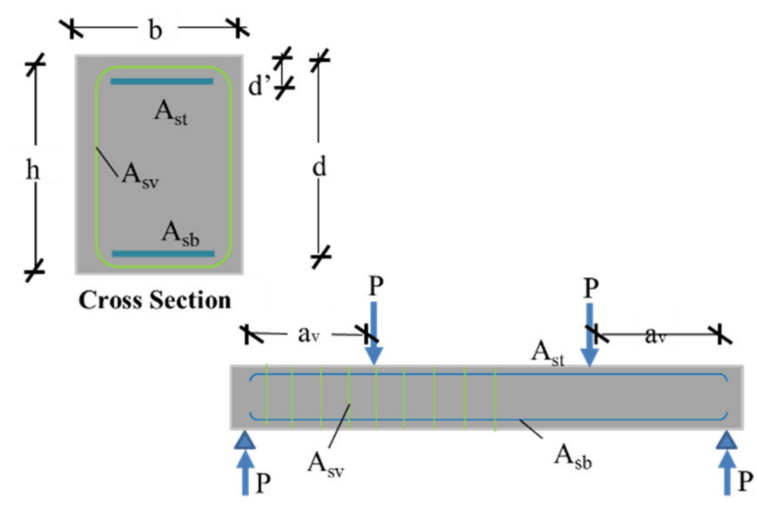

(b)

Figure 4. Simple Loading of (a) Three-point and (b) Four-point Loading for BWS. 
Table 1. Database information for BWOS and BWS DB-I.

\begin{tabular}{|c|c|c|c|c|c|c|c|c|c|c|}
\hline \multicolumn{11}{|c|}{ Beams without Stirrups (BWOS) } \\
\hline & $\mathbf{b}$ & d & av/d & $\rho \mathbf{l}$ & fyl & fc & & & Mf & $\mathbf{V u}$ \\
\hline Unit & $\mathrm{Mm}$ & $\mathrm{Mm}$ & & $(\%)$ & $\mathrm{MPa}$ & $\mathrm{MPa}$ & & & kN-mm & $\mathrm{kN}$ \\
\hline Min & 52 & 70 & 0.329 & 0.25 & 122 & 13 & & & 2000 & 7.25 \\
\hline Max & 500 & 556 & 9.76 & 7.46 & 555 & 112 & & & 844,000 & 585 \\
\hline Avg. & 170 & 264 & 3.75 & 2.21 & 390 & 38 & & & 104,147 & 72 \\
\hline St. Dev & 68 & 85 & 1.55 & 1.1 & 87.26 & 21 & & & 120,894 & 56 \\
\hline $\mathrm{COV}$ & 0.4 & 0.35 & 0.45 & 0.55 & 0.25 & 0.57 & & & 1.2 & 0.82 \\
\hline \multicolumn{11}{|c|}{ Beams with Stirrups (BWS) } \\
\hline & $\mathbf{b}$ & d & av/d & $\rho \mathbf{l}$ & fyl & fc & $\rho w$ & fyw & Mf & Vu \\
\hline Unit & $\mathrm{mm}$ & $\mathrm{mm}$ & & $(\%)$ & $\mathrm{MPa}$ & $\mathrm{MPa}$ & $(\%)$ & $\mathrm{MPa}$ & kN-mm & $\mathrm{kN}$ \\
\hline Min & 100 & 113 & 1 & 0.18 & 250 & 13.8 & 0.08 & 224 & 2648 & 4.097 \\
\hline Max & 510 & 975 & 7.25 & 5.6 & 890 & 126 & 2.25 & 875 & $1,738,423$ & 760.194 \\
\hline Avg. & 208 & 343 & 3.5 & 2.4 & 415 & 45 & 0.6 & 400 & 283,485 & 185.54 \\
\hline St. Dev & 68 & 158 & 1.5 & 1.1 & 78 & 25 & 0.5 & 115 & 378,729 & 134.25 \\
\hline $\mathrm{COV}$ & 0.34 & 0.48 & 0.4 & 0.46 & 0.2 & 0.55 & 0.9 & 0.3 & 1.35 & 0.75 \\
\hline
\end{tabular}

Figure $5 \mathrm{a}, \mathrm{b}$ show the histogram of the different parameters for the BWOS and BWS. This histogram described the frequency of the parameter against the different sample values. This is also a limitation of ANN models, as they will predict against these limits of each parameter. Figure $6 a, b$ provide the values of the correlation parameter, based on these values and the CDC adopted for describing RC structural response at ULS.
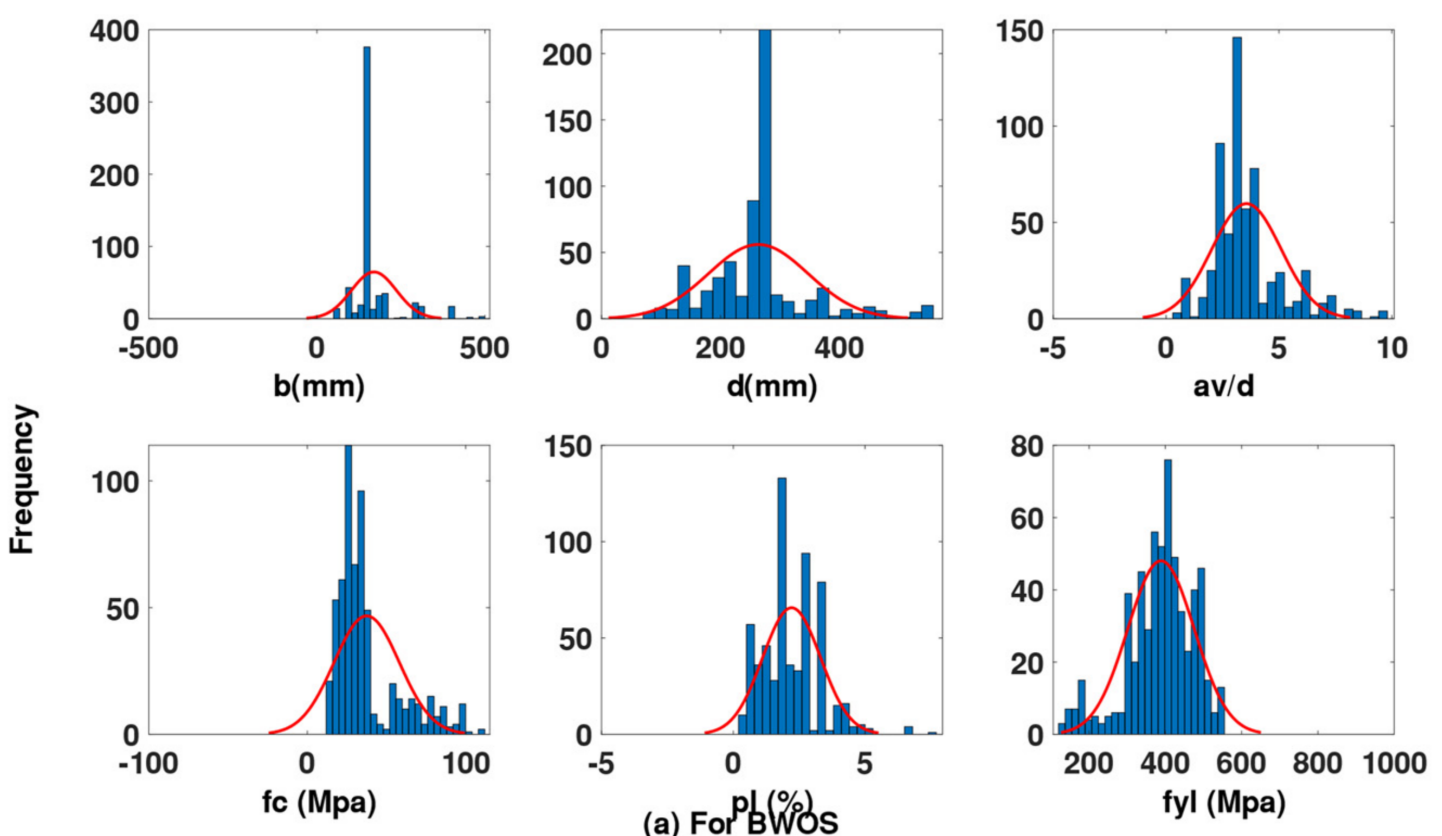

Figure 5. Cont. 

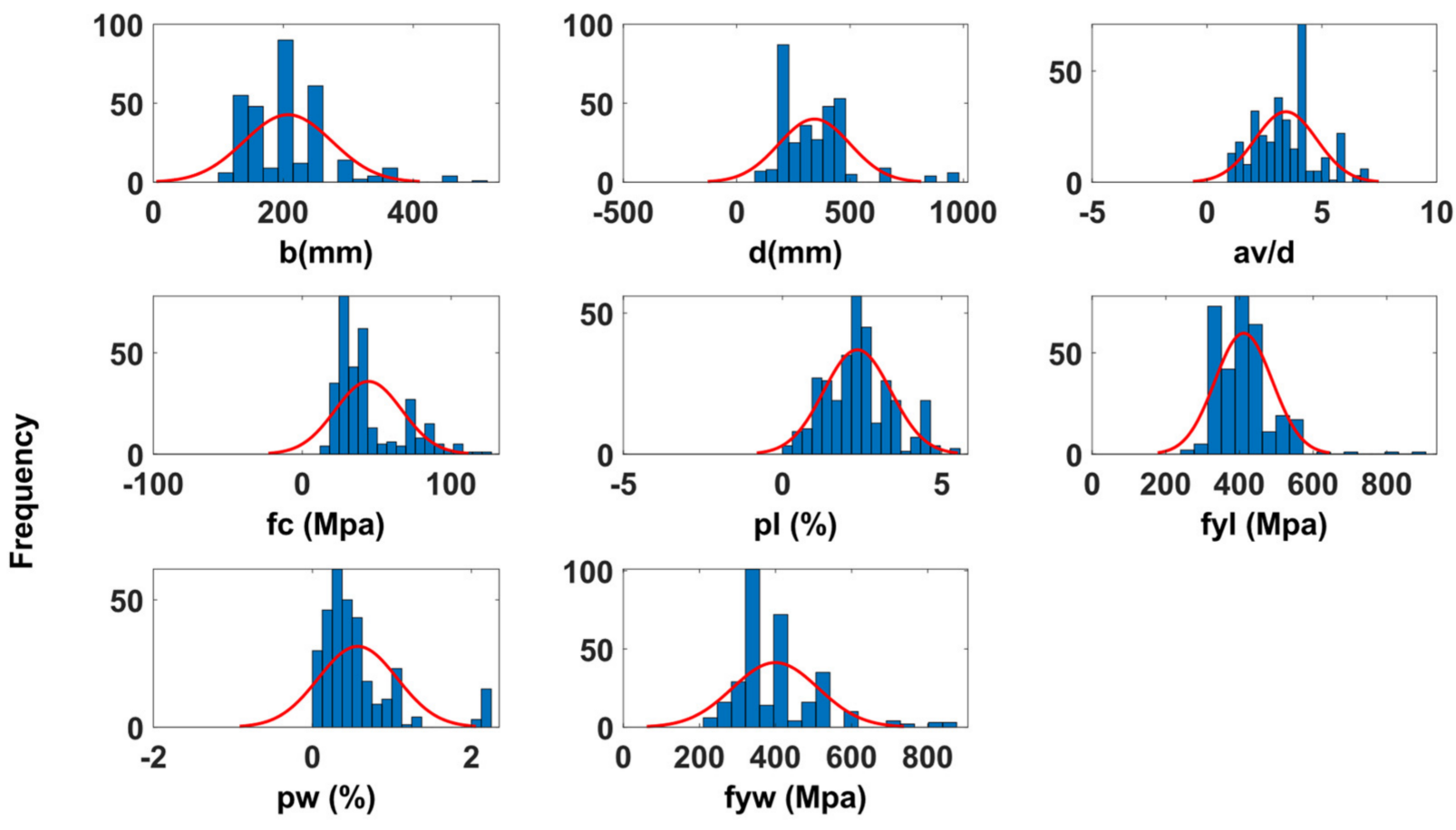

(b) For BWS

Figure 5. Histogram for (a) BWOS and (b) for BWS.
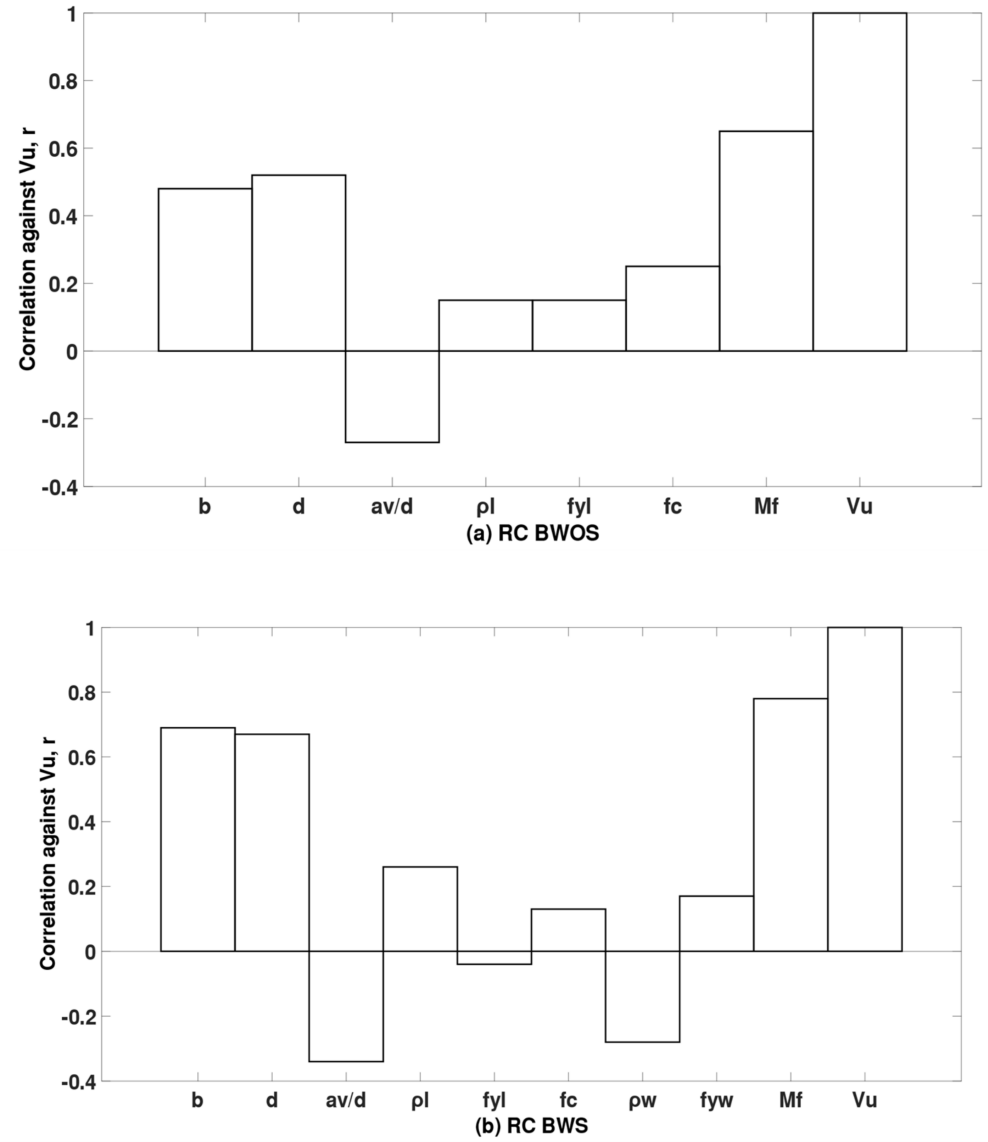

Figure 6. Parametric Correlation r values for (a) BWOS and (b) BWS. 


\subsection{ANN Models for DB-I}

Based on the correlation values, six different ANN models are proposed for RC BWOS and eight for BWS, as described in Table 2. The selection of these ANN models is based on the conventional mechanics' assumption for estimating the $\mathrm{RC}$ member response at the ULS.

Table 2. Input parameters employed by different ANNs -DB-I.

\begin{tabular}{|c|c|}
\hline $\mathbf{V u}$ & \\
\hline \multicolumn{2}{|c|}{ BWOS } \\
\hline EXP & $b, d, \rho_{l}, f_{y l}, f_{c}, a_{v} / d$ \\
\hline BWOS-1 & $b, d, \rho_{l}, f_{y l}, f_{c}, a_{v} / d$ \\
\hline BWOS-2 & $b, d, M_{f}, f_{c}, a v / d$ \\
\hline BWOS-3 & $b / d, M_{f} / f_{c} b d^{2}, a_{v} / d$ \\
\hline BWOS-4 & $d, M_{f} / b d^{2}, f_{c}, a_{v} / d$ \\
\hline BWOS-5 & $d, b / d, M_{f} / f_{c} b d^{2}, a_{v} / d$ \\
\hline BWOS-6 & $d, b / d, M_{f} / f_{c} b d^{2} f_{c}, a_{v} / d$ \\
\hline \multicolumn{2}{|c|}{$B W S$} \\
\hline EXP & $b, d, \rho_{l}, f_{y l}, f_{c}, \rho_{w w}, f_{y w}, a_{v} / d$ \\
\hline BWS-1 & $b, d, \rho_{l}, f_{y l}, f_{c}, \rho_{w w}, f_{y w}, a_{v} / d$ \\
\hline BWS-2 & $b, d, M_{f}, f_{c}, \rho_{w w}, f_{y w}, a_{v} / d$ \\
\hline BWS-3 & $b / d, M_{f} / f_{c} b d^{2}, \rho_{w}, f_{y w}, a_{v} / d$ \\
\hline BWS-4 & $b / d, \rho_{w} / \rho_{l}, f_{c} / f_{y w}, a_{v} / d$ \\
\hline BWS-5 & $d, M_{f} / b d^{2}, f_{c}, \rho_{w w} f_{y w}, a_{v} / d$ \\
\hline BWS-6 & $d, b / d, M_{f} / f_{c} b d^{2}, \rho_{w}, f_{y w}, a_{v} / d$ \\
\hline BWS-7 & $d, b / d, M_{f} / f_{c} b d^{2}, f_{c}, \rho_{w}, f_{y w}, a_{v} / d$ \\
\hline BWS-8 & $d, b / d, M_{f} / f_{c} b d^{2}, f_{c}, \rho_{w} f y_{w}, a_{v} / d$ \\
\hline
\end{tabular}

Figure 7a,b describe the outcome of the different ANN models for the DB-I for the BWOS and BWS with their counterpart experimental values. Figure $8 \mathrm{a}, \mathrm{b}$ describe the performance of these ANN models with respect to the R, MSE and MAE (as discussed earlier). Therefore, from Figures 7 and 8, it is observed the BWOS-4 (i.e., $d, M_{f} / b d^{2}, f_{c}, a_{v} / d$ ) and BWS-7 (i.e., $d, b / d, M f / f_{c} b d^{2}, f_{c}, \rho w, f_{y w}, a_{v} / d$ ) achieved a reasonably good value of $R$ while showing the minimum values of MSE and MAE as compared to the other models.
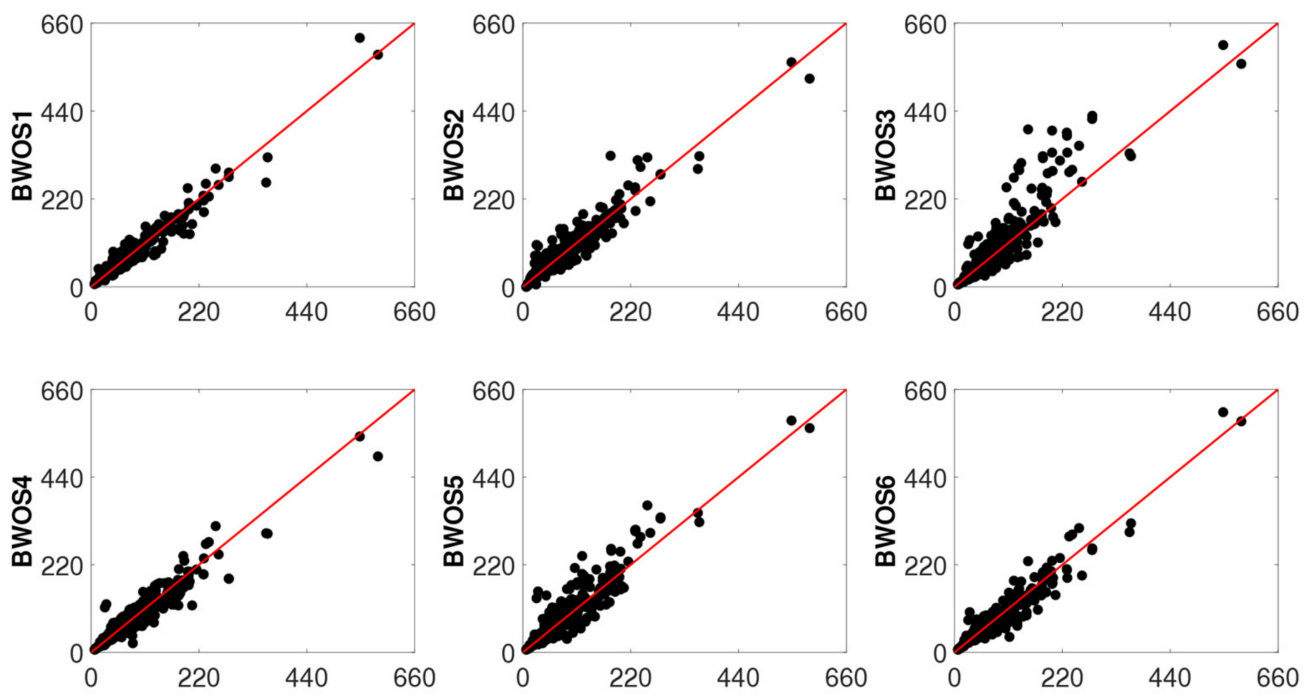

(a) BWOS EXPERIMENTAL

Figure 7. Cont. 

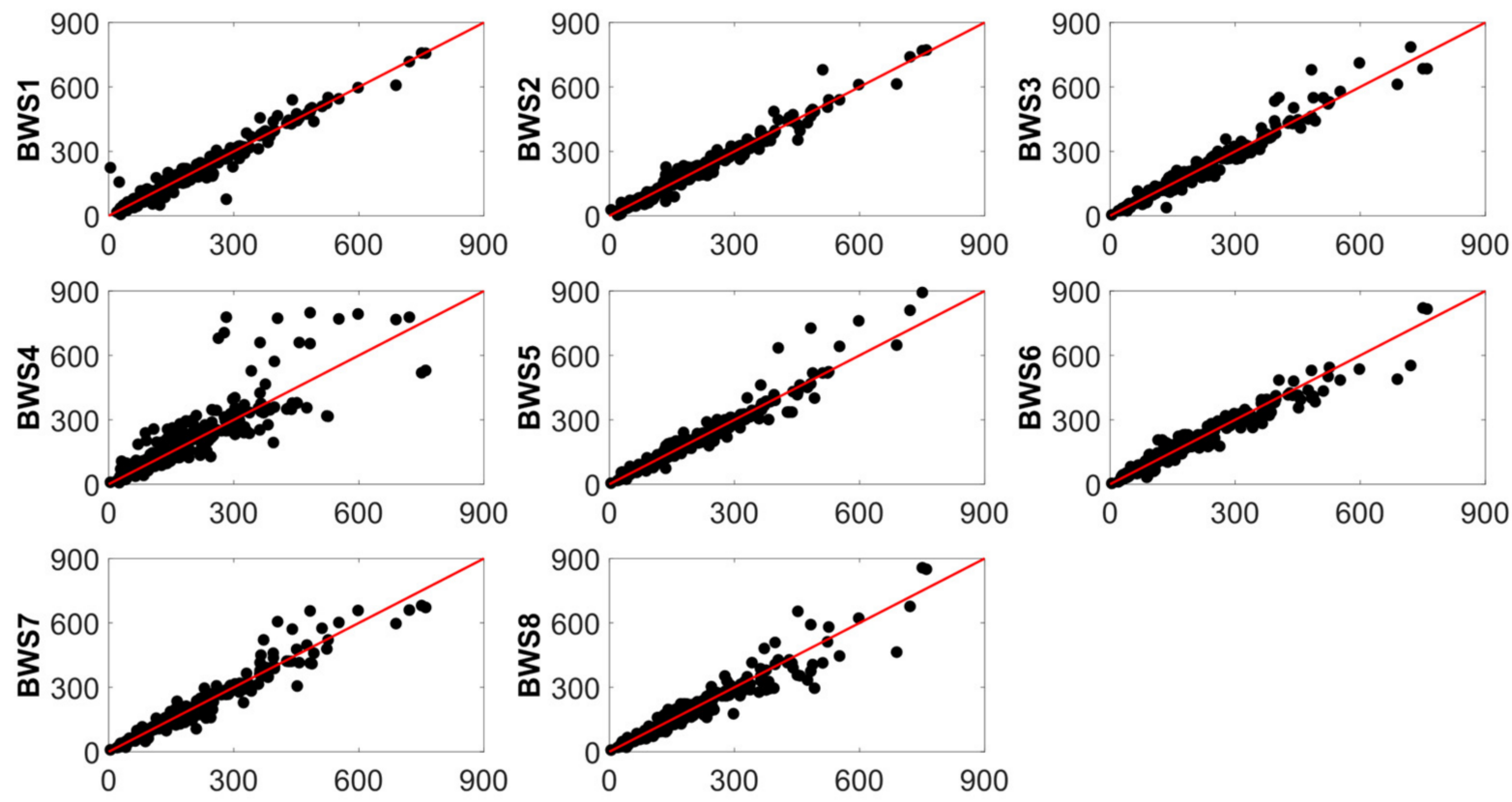

(b) BWS EXPERIMENTAL

Figure 7. ANNs Models for (a) BWOS and (b) BWS.
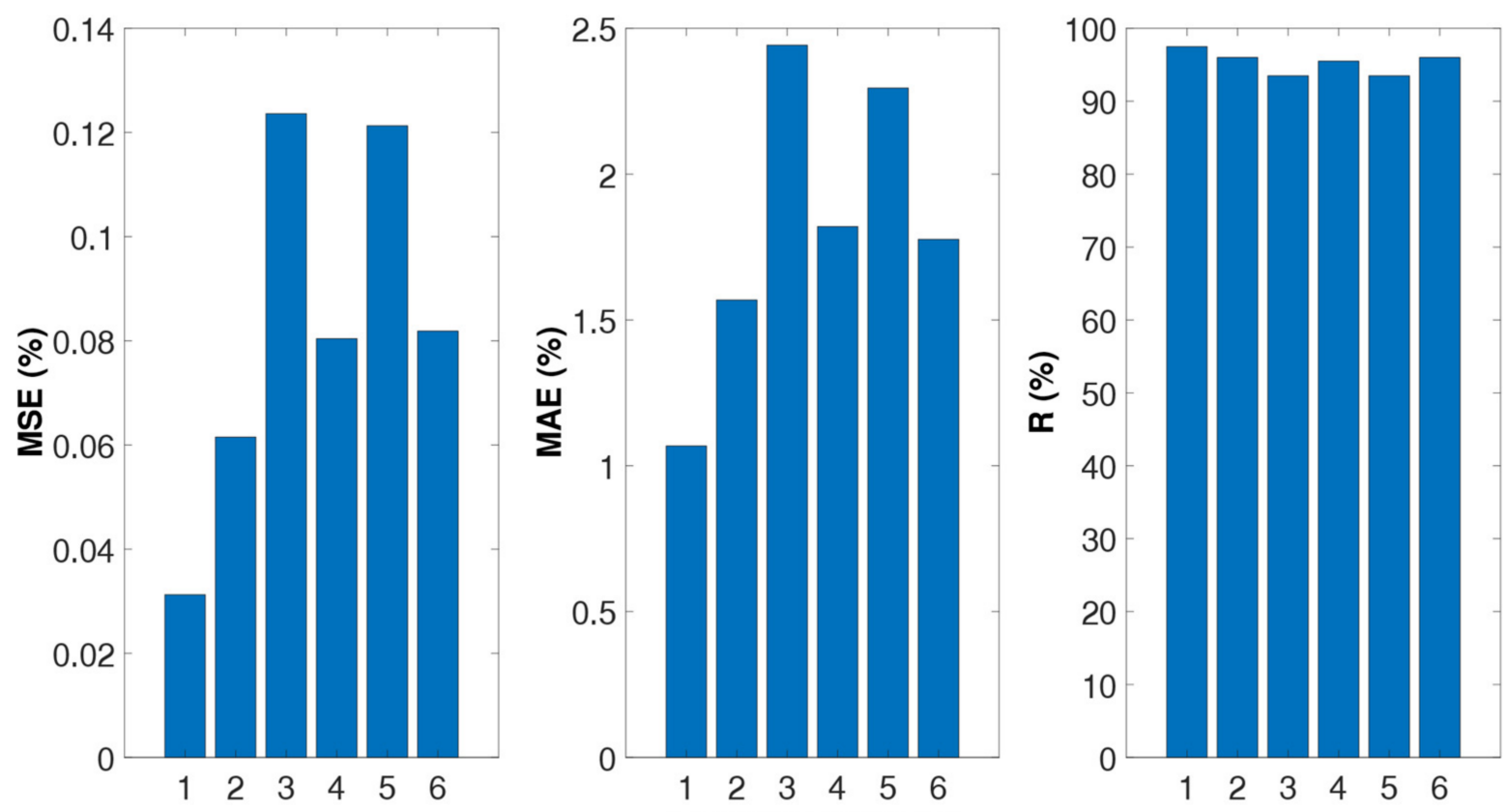

(a) BWOS MODELS

Figure 8. Cont. 

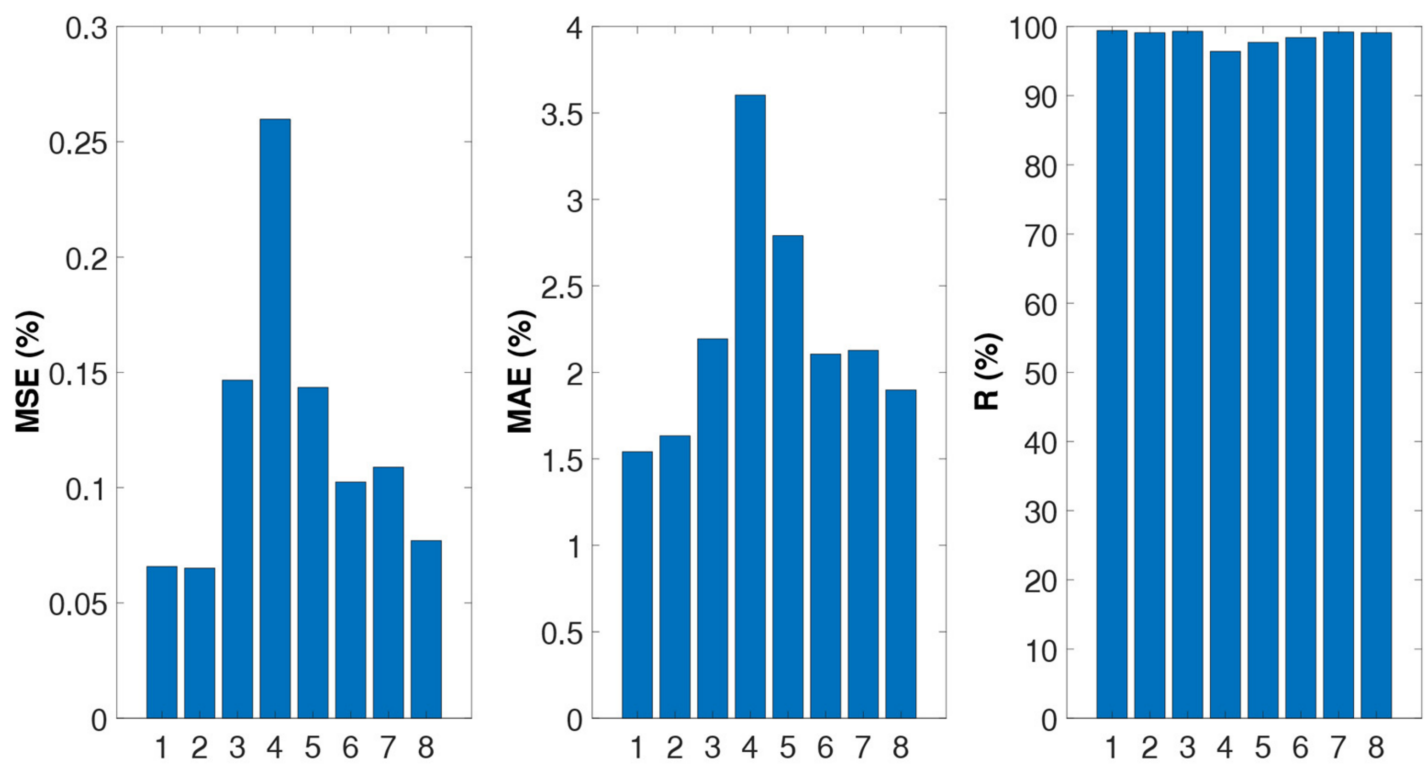

(b) BWS MODELS

Figure 8. Error between of ANNs models for (a) BWOS and (b) BWS.

\subsection{Comparative Studies for DB-I}

This section describes the comparative study between the prediction values of the models mentioned above with the CDC [1,2], the alternative CFP method [14], the optimized ANN models, i.e., BWOS-4 and BWS-7 with the provided experimental values. From Figure 9a,b, the ANN, CDCs i.e.,EC2 and the CFP the method seems to be able to provide at least a prediction that can be compared to the values of the counterparts, even though CFP and ANN are based on different approaches as compared to their counterpart CDC equations.
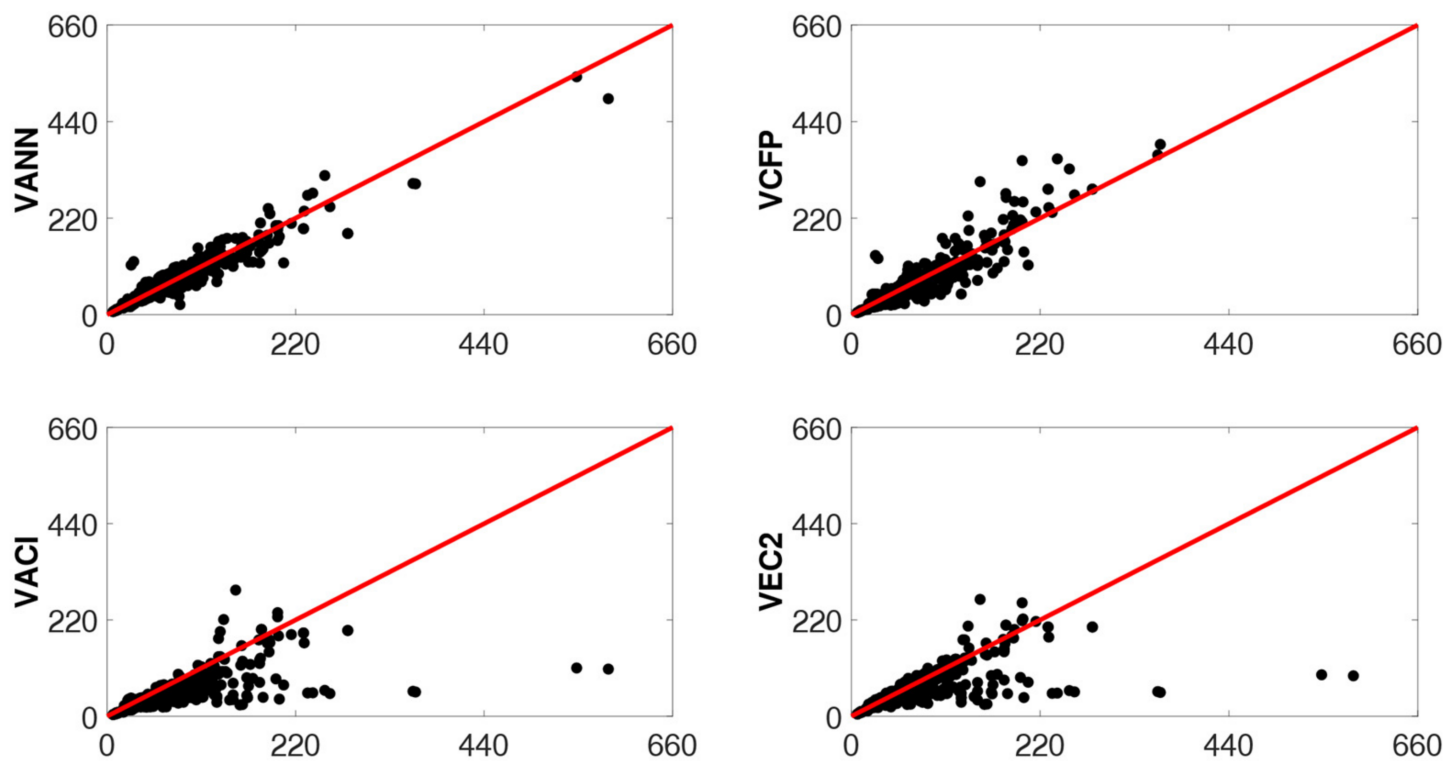

(a) BWOS EXPERIMENTAL

Figure 9. Cont. 

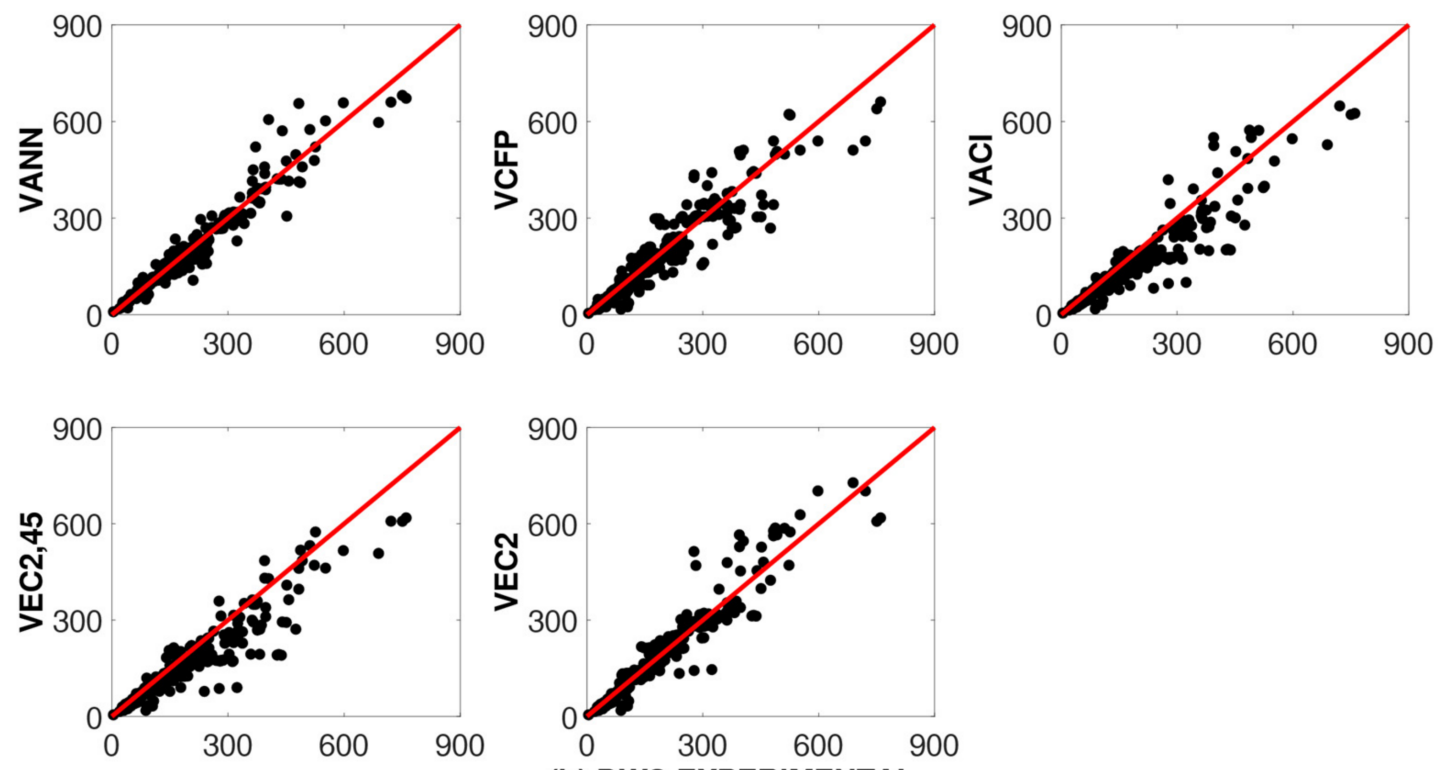

(b) BWS EXPERIMENTAL

Figure 9. Comparative Study for (a) BWOS and (b) BWS.

Figure 10a shows the Gaussian distribution (GD) of the $V_{\text {Exp }} / V_{\text {Pred }}$ ratios stating the experimental values $\left(V_{\text {Exp }}\right)$ normalized by their predicted counterparts $\left(V_{\text {Pred }}\right)$ provided by CDC, CFP and the ANN. The ANN predictions show the best GD by showing a value close to the 1 . The predictions obtained from the CFP are also very close to the provided experimental results as related to the CDC, for BWOS. The ratio CFP (VExp/VCFP) results are very close to the findings of ANN compared to CDCs for the BWOS. Similarly, in Figure $10 \mathrm{~b}$ the results obtained from the CDCs, i.e., EC2 are closer to the ANN results as related to the CDC, for BWS. The other physical models' predictions have mostly underestimated the predictions compared to the ANN models and CFP method. The assumptions obtained in the form of EC2 $\left(\mathrm{V}_{\mathrm{EXP}} / \mathrm{V}_{\mathrm{EC} 2}\right)$ are very close to the ANN findings.

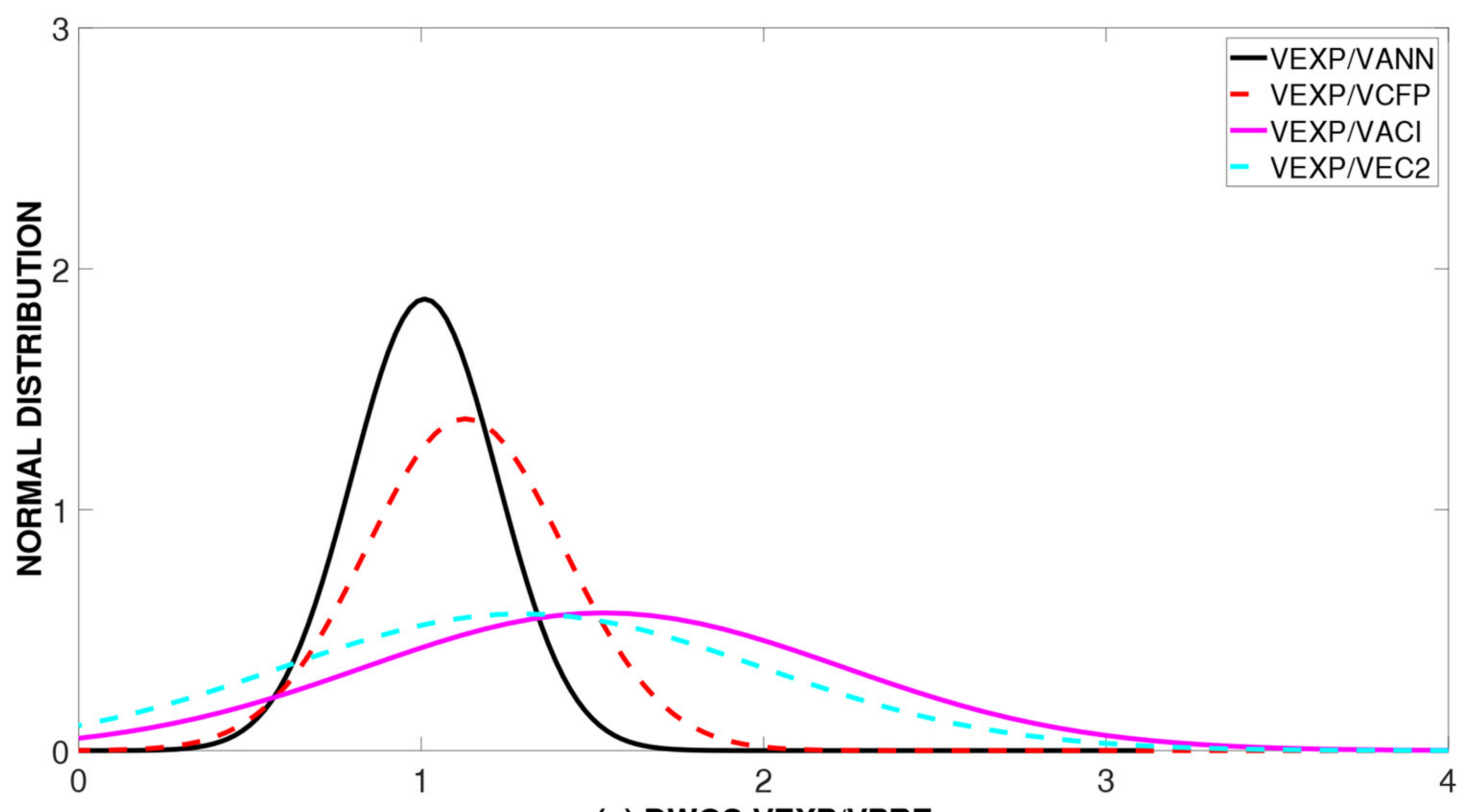

(a) BWOS VEXP/VPRE

Figure 10. Cont. 


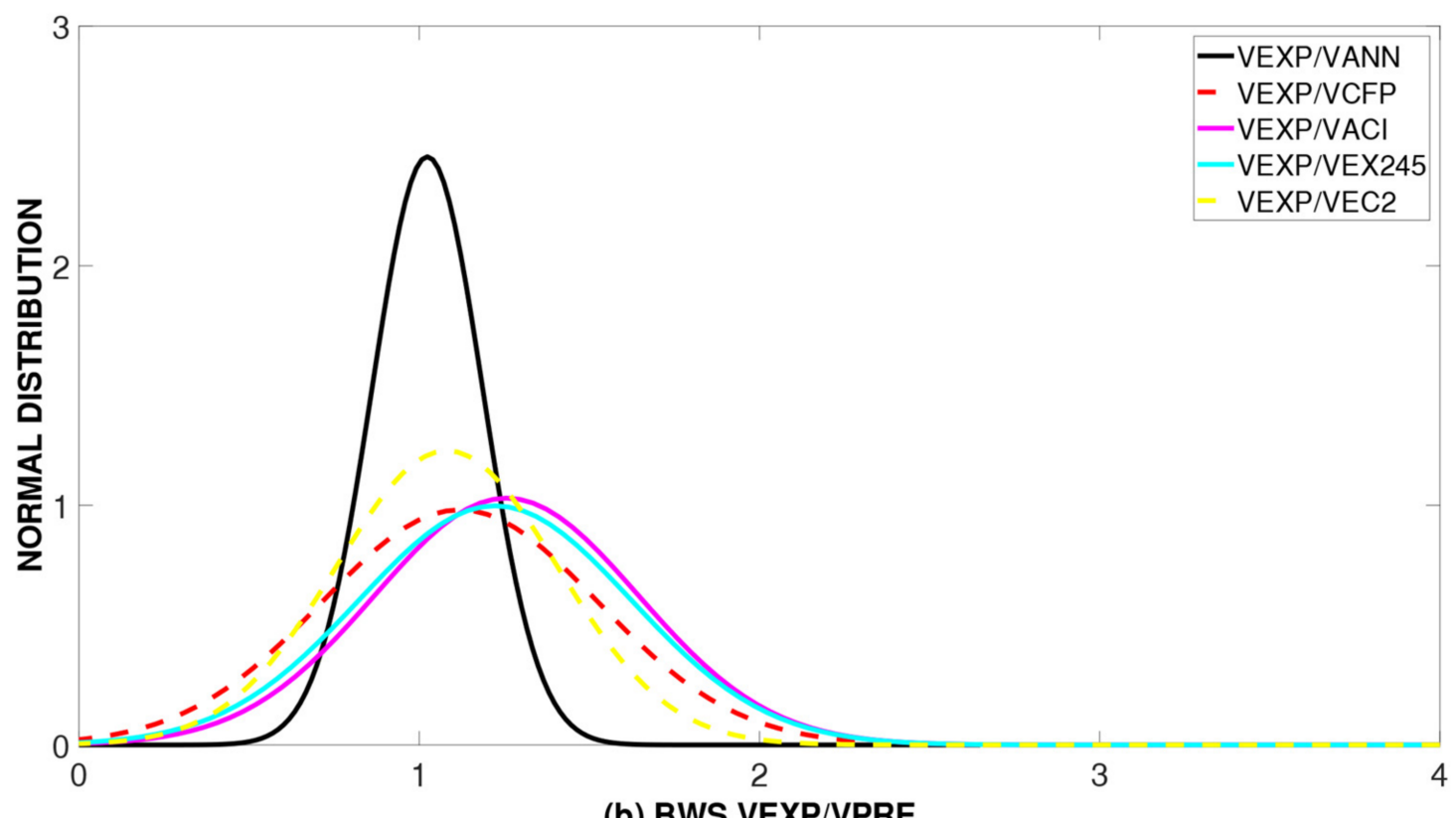

(b) BWS VEXP/VPRE

Figure 10. Normal Distribution for (a) BWOS and (b) BWS.

Figure 11a describes the variation of the predicted ratios, with respect to overestimation or underestimation. It therefore appears that the CDC (ACI and EC2) tends to underestimate the load capacity, in contrast to ANN and CFP, where $92 \%$ of the results are in the correct range (i.e., from 0.755 to 1.255 ) of the BWOS. Similarly, Figure $11 \mathrm{~b}$ shows that CFP, ACI and EC2-45 generally underestimate the carrying capacity, in contrast to ANN and the CDCs i.e., EC2 in the precise range (i.e., from 0.755 to 1.255) of the BWS. The other physical models' predictions mostly underestimate the predictions compared to the ANN models and CFP method.

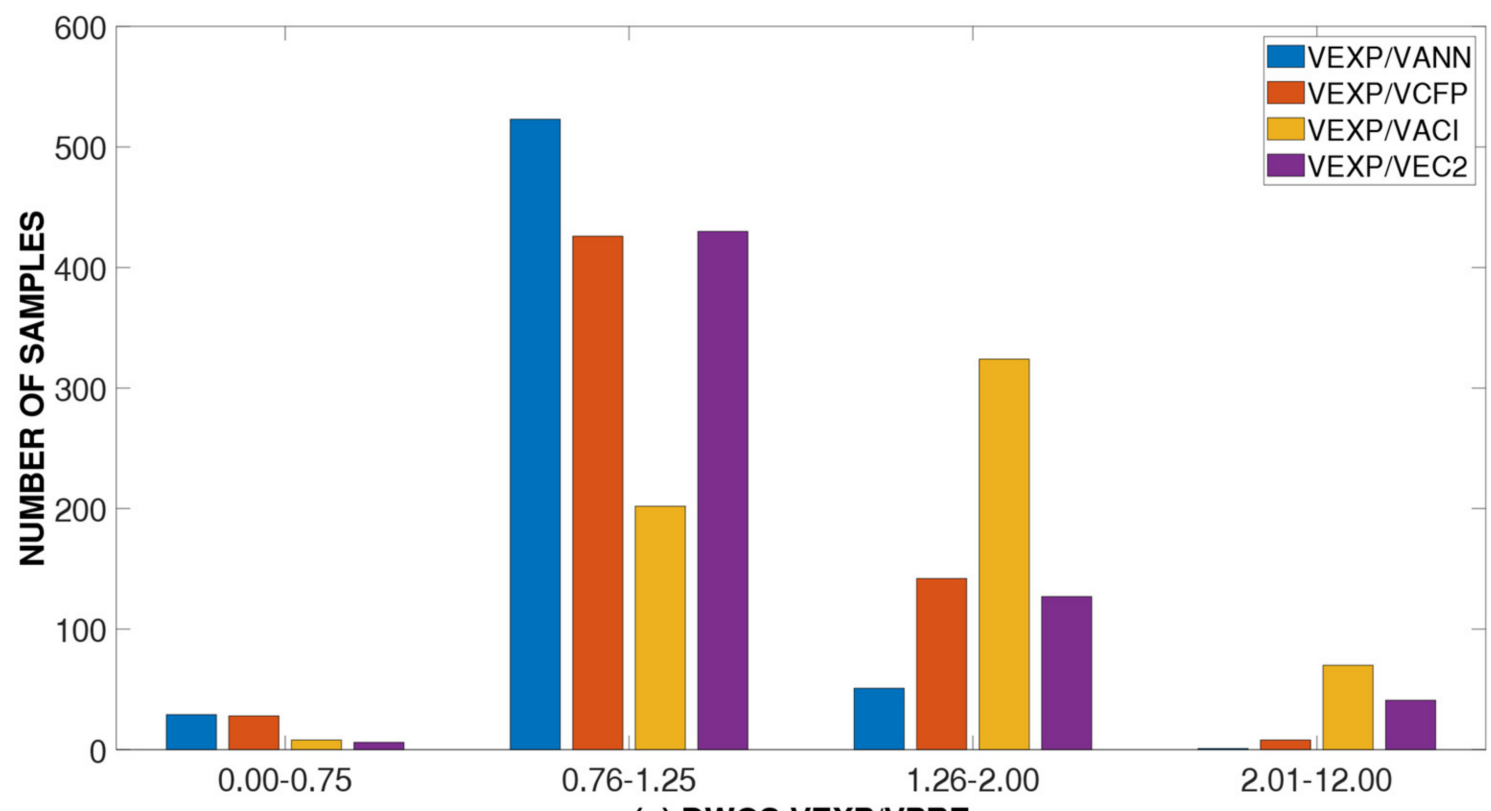

(a) BWOS VEXP/VPRE

Figure 11. Cont. 


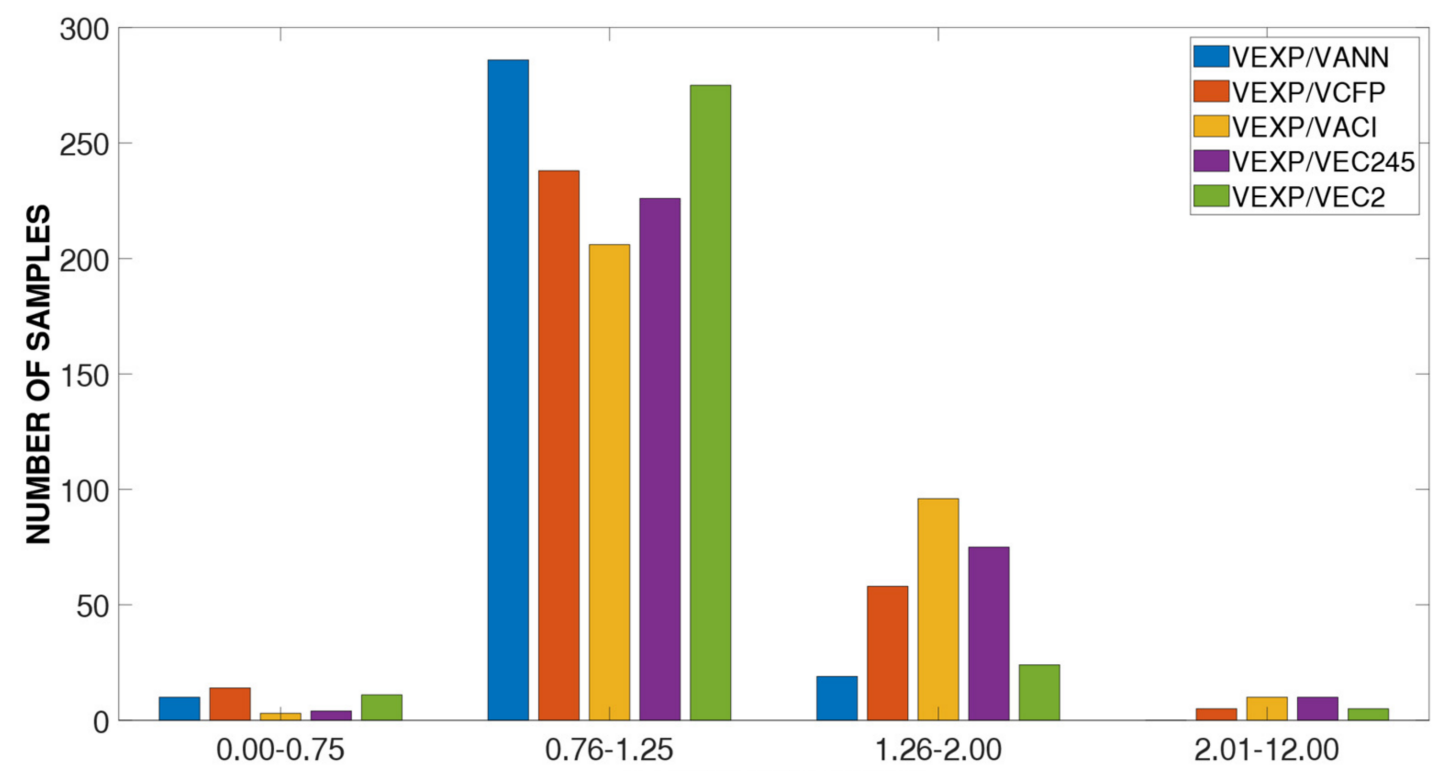

(b) BWS VEXP/VPRE

Figure 11. Ratios distribution for (a) BWOS and (b) BWS.

\section{Database-II: CWA}

The second database (DB-II) includes 130 samples of RC columns (CWA), with cantilever support conditions, as shown in Figure 12. Table 3 describes the statistical information of the parameter for this DB-II. Here $62 \%$ of samples (e.g., 80) show shear failure mode and another 38\% (e.g., 50) samples show flexural failure mode. Figure 13 describes the result $\mathrm{r}$ for the DB-II.

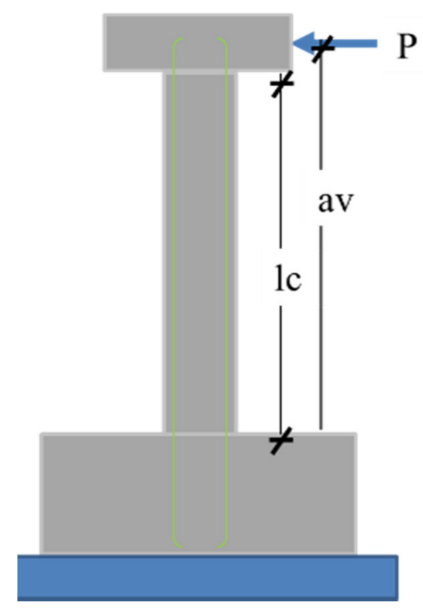

Figure 12. Experimental setup for RC columns (CWA).

Table 3. Database information for DB-III (CWA).

\begin{tabular}{cccccccccccc}
\hline & $\mathbf{b}$ & $\mathbf{d}$ & $\mathbf{a v} / \mathbf{d}$ & $\boldsymbol{\rho} \mathbf{1}$ & $\mathbf{f y l}$ & $\mathbf{f c}$ & $\boldsymbol{\rho w}$ & $\mathbf{f y w}$ & $\mathbf{N}$ & $\mathbf{M f}$ & $V_{\boldsymbol{u}}$ \\
\hline & $\mathbf{( m m})$ & $\mathbf{( m m )}$ & & $\mathbf{( \% )}$ & $\mathbf{( M P a )}$ & $\mathbf{( M P a )}$ & $\mathbf{( \% )}$ & $\mathbf{( M P a )}$ & $\mathbf{( k N )}$ & $\mathbf{k N}-\mathbf{m m}$ & $\mathbf{( k N )}$ \\
\hline Min & 150 & 110.5 & 2.647 & 0.87 & 313 & 17.9 & 0.1 & 255 & 111 & 15 & 33 \\
Max & 550 & 470 & 8.73362 & 6.16 & 559.5 & 118 & 2.8 & 1424 & 5373 & 1590 & 812 \\
Avg. & 323.03 & 241.22 & 5.1 & 3.19 & 463.16 & 49.09 & 0.82 & 497.46 & 1445.62 & 366.91 & 244.04 \\
St. Dev & 117.16 & 77.37 & 1.57 & 1.15 & 50.13 & 28.23 & 0.58 & 246.1 & 1270.2 & 337.62 & 177.62 \\
COV & 0.36 & 0.32 & 0.31 & 0.36 & 0.11 & 0.58 & 0.71 & 0.49 & 0.88 & 0.92 & 0.73 \\
\hline
\end{tabular}




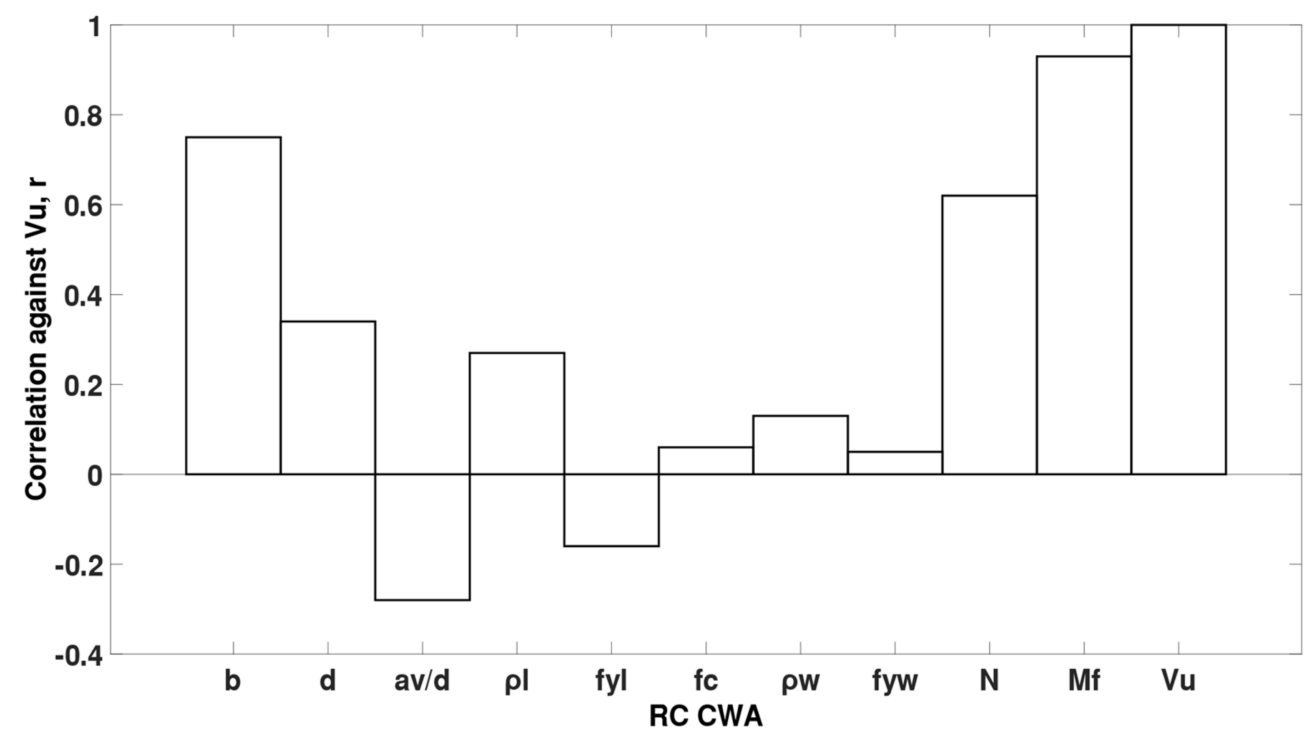

Figure 13. Parametric correlation $r$ for CWA parameters.

Figure 14 illustrates the histogram for these critical parameters for the CWA. This histogram describes the frequency of the parameter against the different sample val-ues. This is also a limitation of the ANN models, as they will predict against these lim-its of each parameter.
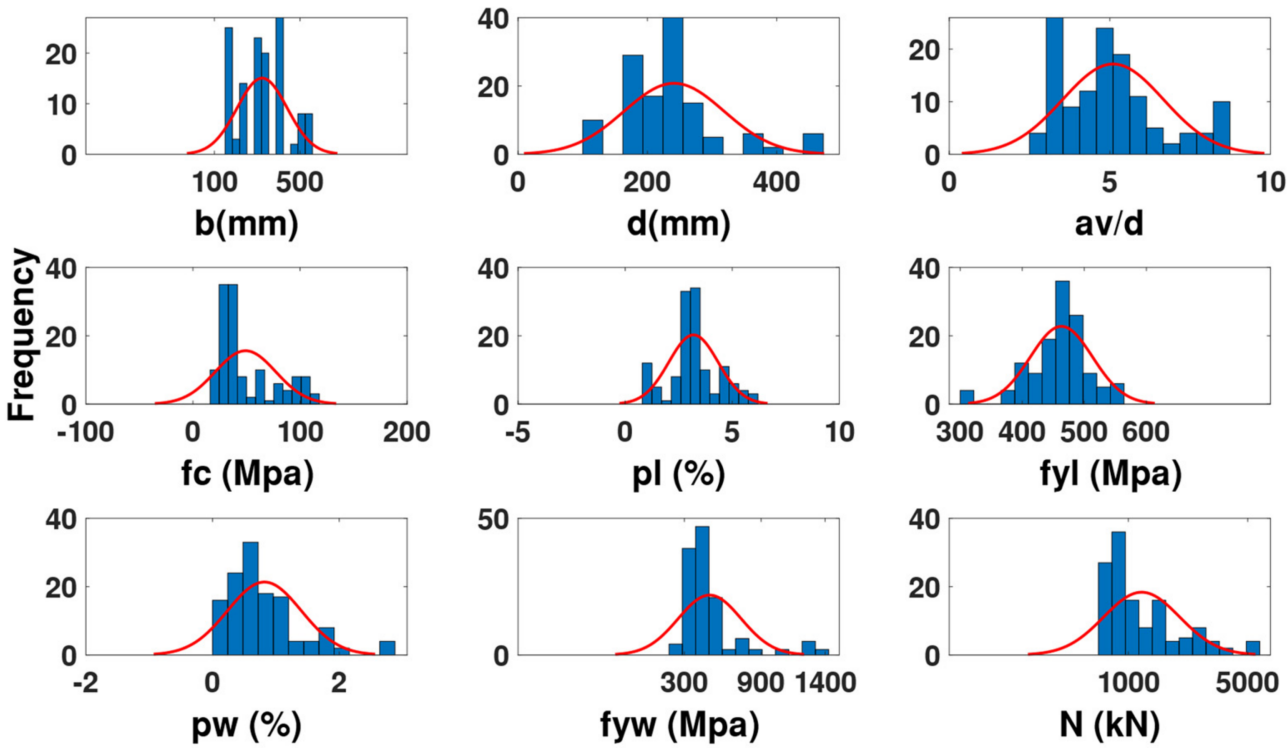

Figure 14. Histogram for CWA parameters.

\subsection{ANN Models for DB-II}

Based on the $r$ values, nine different ANN models are proposed for the DB-II i.e., CWA as described in the Table 4. 
Table 4. Proposed ANN Models for the DB-II.

\begin{tabular}{cc}
\hline & Parameters \\
\hline DB-II & \\
CWA:1 & $b, d, \rho_{l}, N, f_{y l}, f_{c}, \rho_{w}, f_{y w}, a_{v} / d$, \\
CWA:2 & $b, d, M_{f}, N, f_{c}, \rho_{w}, f_{y w}, a_{v} / d$, \\
CWA:3 & $b / d, N / b d f_{c}, \rho_{w}, f_{y w}, M_{f} / f_{c} b d^{2}, a_{v} / d$, \\
CWA:4 & $b / d, N / b d f_{c}, f_{c} / f_{y w}, \rho w / \rho l, a_{v} / d$, \\
CWA:5 & $d, N / b d f_{c}, \rho_{w} f_{y w}, M_{f} / f_{c} b d^{2}, f_{c}, a_{v} / d$, \\
CWA:6 & $d, b / d, N / b d f_{c}, \rho_{w}, f_{y w}, M_{f} / f_{c} b d^{2}, a_{v} / d$, \\
CWA:7 & $d, b / d, N / f_{c} b d, \rho_{w}, f_{y w}, M_{f} / f_{c} b d^{2}, f_{c}, a_{v} / d$, \\
CWA:8 & $d, b / d, N / f_{c} b d, \rho_{w} f_{y w}, M_{f} / f_{c} b d^{2}, f_{c}, a_{v} / d$ \\
CWA:9 & $d, b / d, \rho_{w}, f_{y w}, M_{f} / f_{c} b d^{2}, f_{c}, a_{v} / d$, \\
\hline
\end{tabular}

From Figures 15 and 16 the CWA-3 (i.e., $b / d, N / b d f_{c}, M f / f_{c} b d^{2}, \rho_{w}, f_{y w}, a_{v} / d$ ) is observed with a maximum $R$ and with minimum values of MAE and MSE.
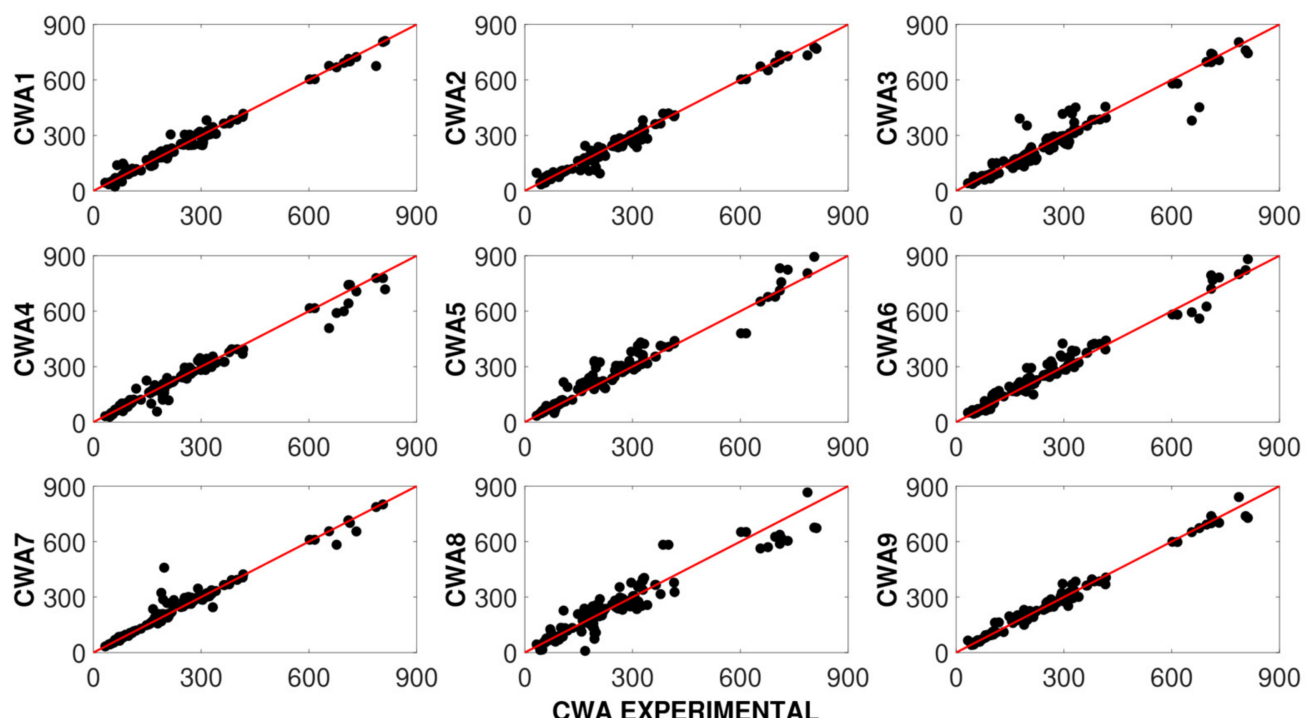

Figure 15. ANN models for CWA.
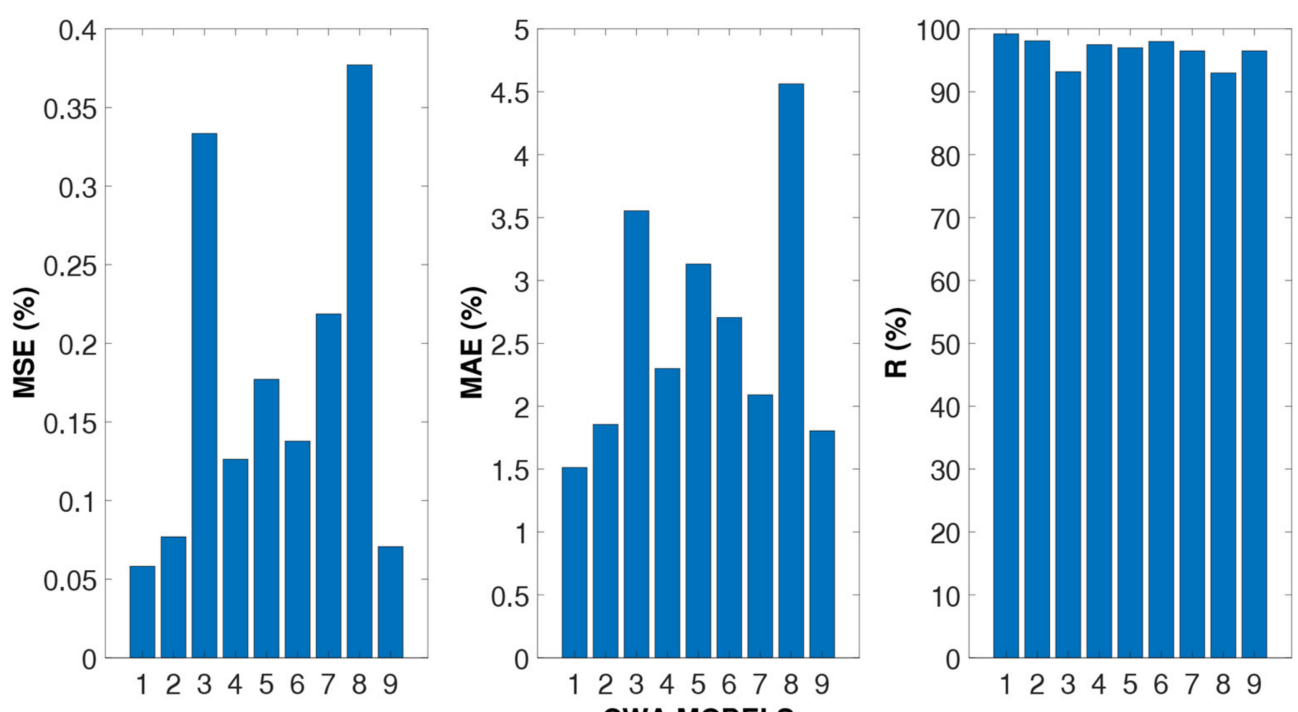

Figure 16. Error performance for CWA. 


\subsection{Comparative Studies for DB-II}

In this section, a comparative study is carried out between the abovementioned models for the CWA-3 as described in the Figures 17-19 for the database DB-II. Figure 17 explains that the non-conventional models, i.e., ANN and CFP methods, are able to provide at least a comparable prediction comparable to their established counterparts by testing and using CDCs. Having heuristic methods that are not strictly in line with the principles of theoretical equipment, the predictions of the ANN models appear to be able to provide predictions that provide close proximity to available experimental data compared to the available predictive design codes. Furthermore, it is fair to say that although based on assumptions that do not conform to the CFP approach is able to provide shear strength predictions close to the provided experimental values as related to those found in design codes.
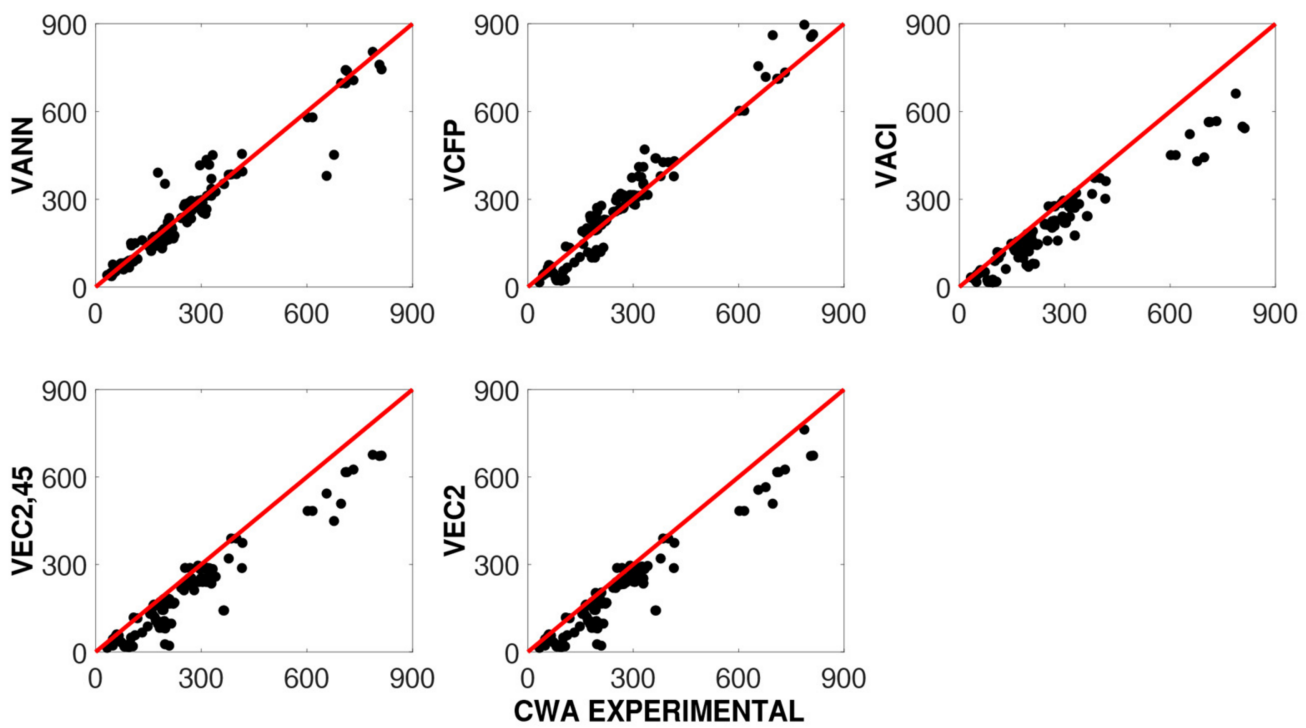

Figure 17. Comparative study for CWA.

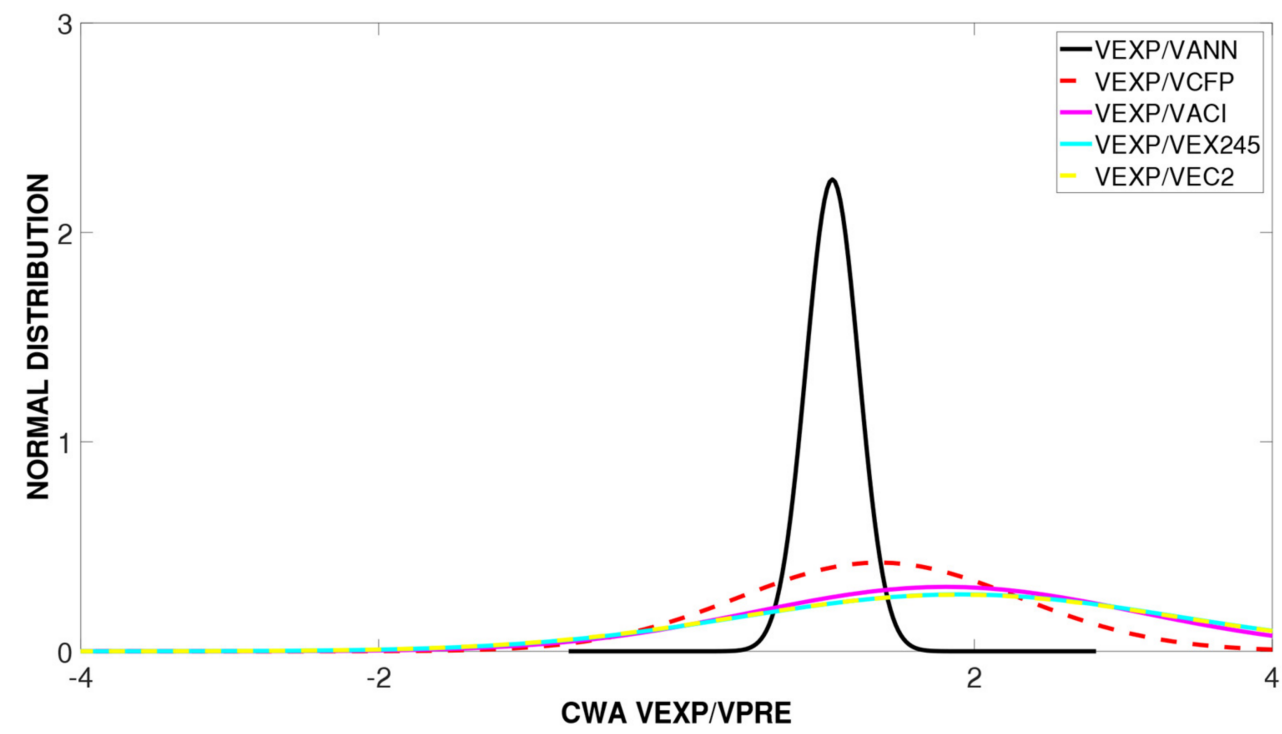

Figure 18. Normal Distribution for CWA. 


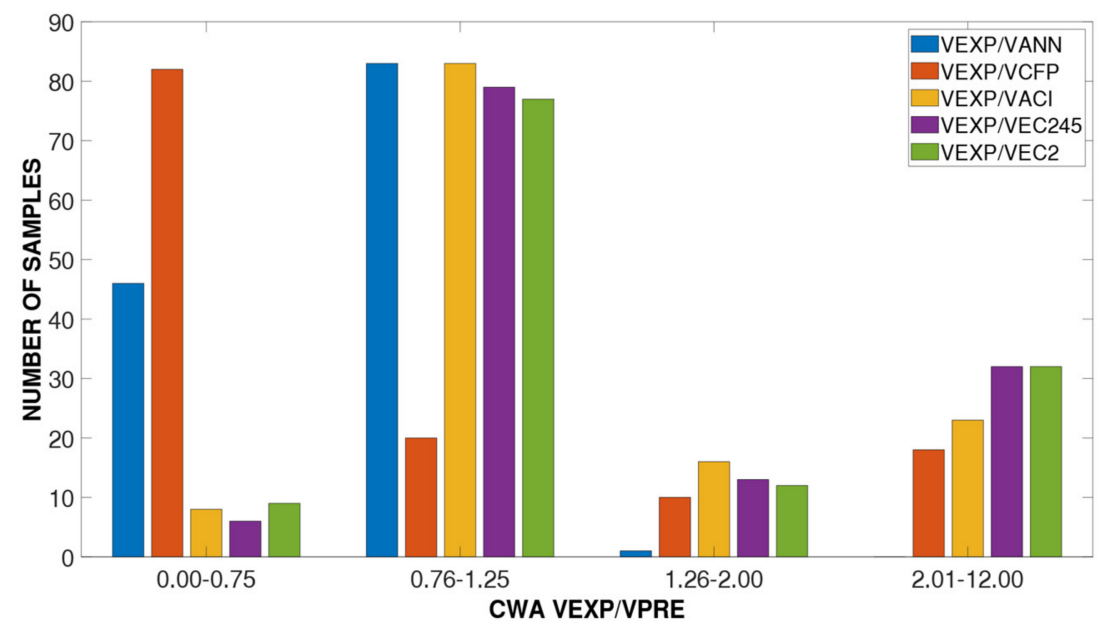

Figure 19. Ratio distribution for CWA.

Figure 18 shows that the non-conventional models i.e., ANN and CFP methods, are able to provide at least predictions that can be compared to their CDC counterparts. As for the CWA, the forecasts obtained from the ANNs show an excellent GD, indicated by the lowest ST. The DEV is 1.05 for CWA samples and 1.36 for CFP. Figure 19 exposes the variation of overestimation or underestimation of the member response at ULS. It is observed that the results of the CDCs (ACI and EC2) are mostly low as related to the experimental values when compared to the results of the non-conventional models i.e., ANN and CFP, i.e., 80 (i.e., from 0.01 to 1.255). The other physical models' predictions give mostly underestimated predictions as they relate to the ANN models and CFP method.

\section{Database-III: TBWOS and TBWS}

In the third database (DB-III), two complex members RC T-beams in simply supported conditions without transverse steel or stirrups (TBWOS) and with transverse steel or stirrups (TBWS) as shown in Figure 20a,b are developed from the literature [13].
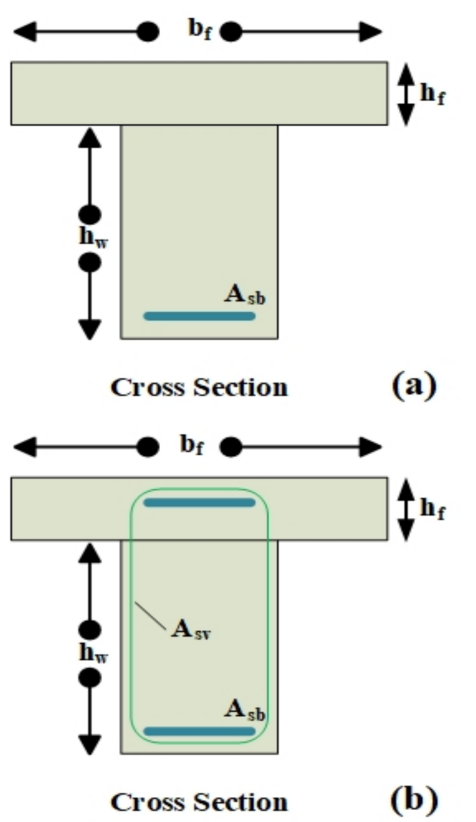

(b)
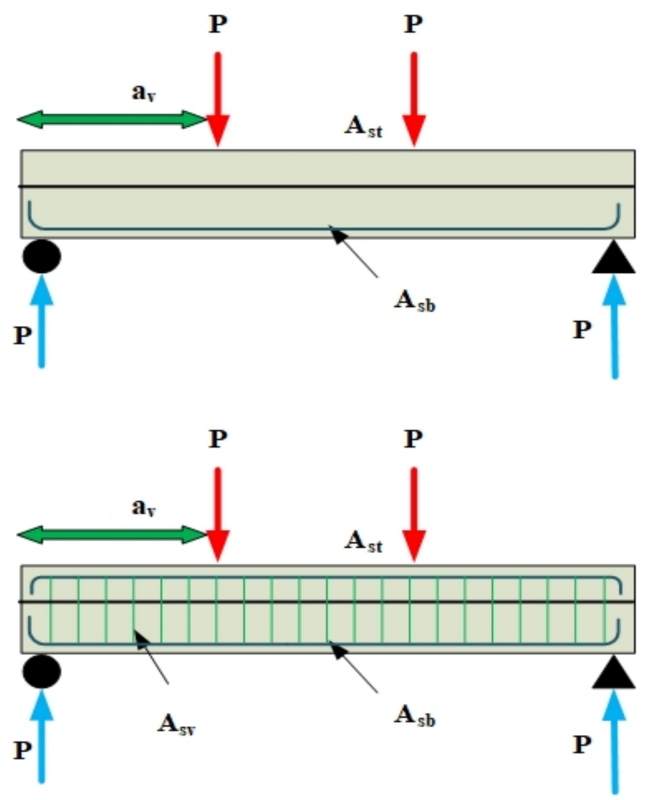

Figure 20. Loading condition for (a) TBWOS and (b) TBWS. 
Of the 30 samples from TBWOS, $60 \%$ of these samples (e.g., 18) showed a shear failure mode and the remainder showed a variable mode of failure. For TBWS, 57 trials of these $98 \%$ samples (e.g., 56) are on-site showing shear failure mode and the remaining indicating variable failure mode. Figure $21 \mathrm{a}, \mathrm{b}$ shows the histogram for the parameters for the TBWOS and TBWS. This histogram describes the frequency of the parameters against the different sample values. This is also the limitation of the ANN models, as they will predict against these limits of these parameters. Table 5 provides detailed information about the parameters of the DB-III.
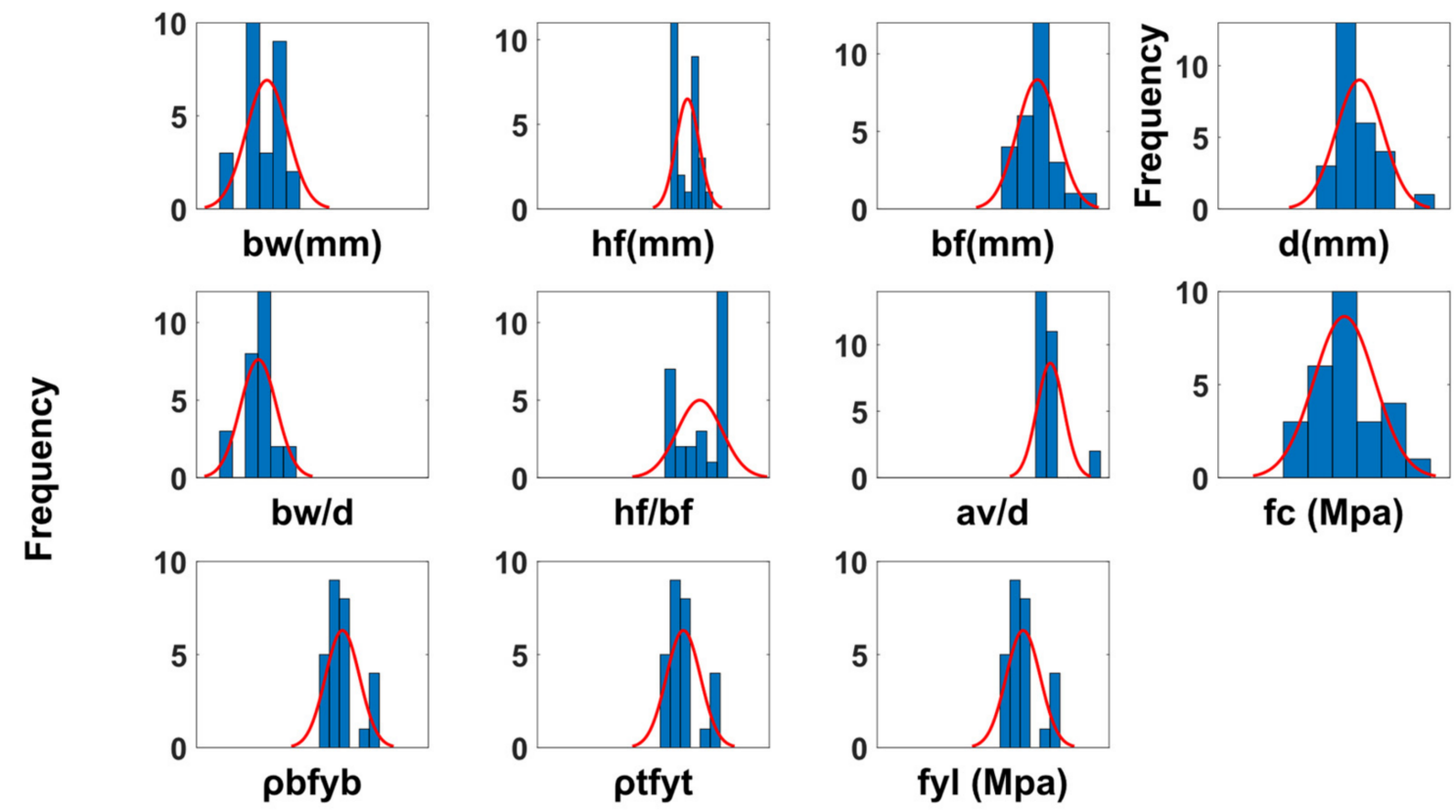

(a) For TBWOS
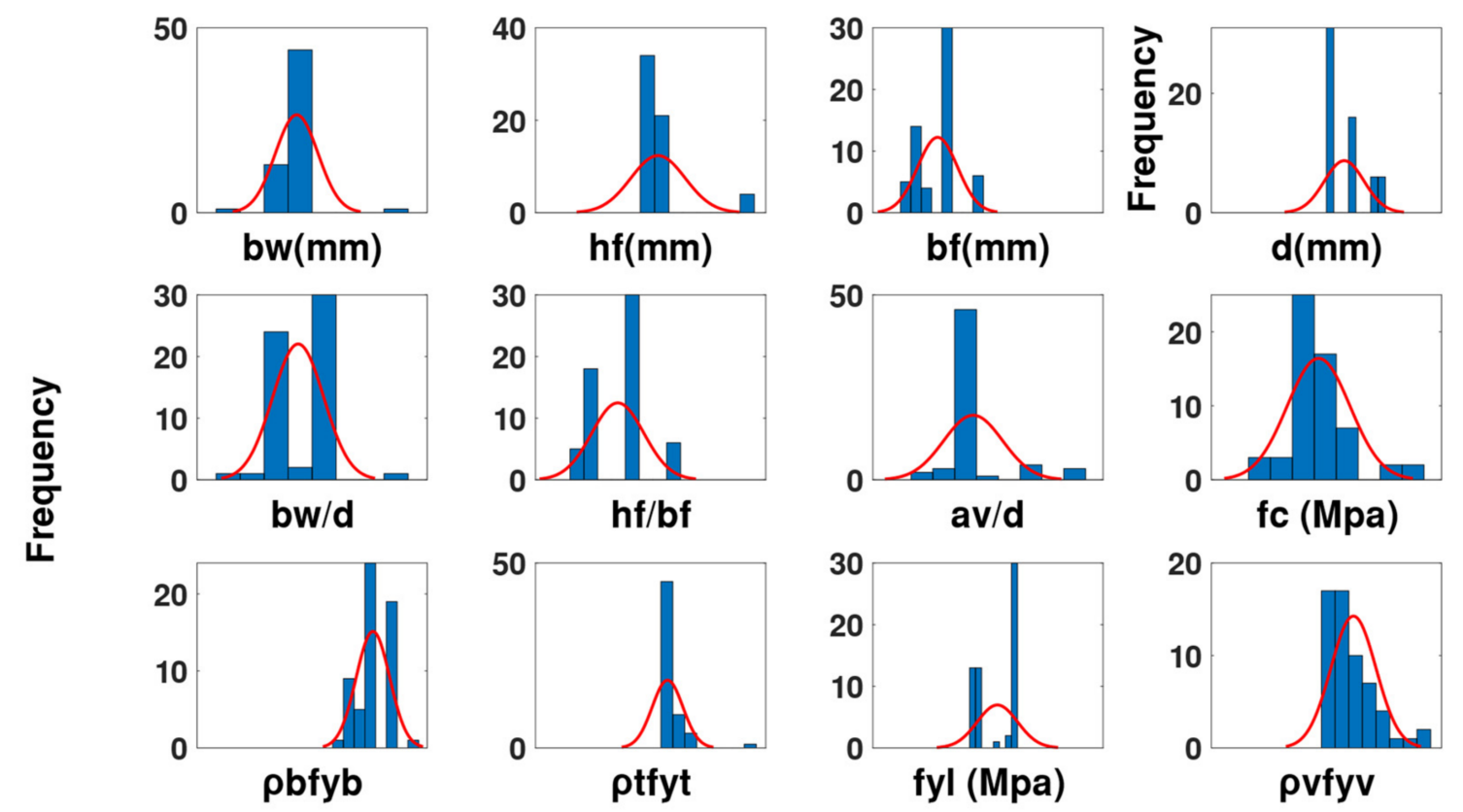

(b) For TBWS

Figure 21. Histogram for the parameters for (a) TBWOS and (b) TBWS. 
Table 5. Database information for DB-III.

\begin{tabular}{|c|c|c|c|c|c|c|}
\hline \multicolumn{7}{|c|}{ Detail of the Database TBWOS } \\
\hline & & Min & Max & Mean & St. Dev & $\mathrm{COV}$ \\
\hline$f_{c}$ & $\mathrm{MPa}$ & 18 & 47 & 31 & 7.56 & 0.23 \\
\hline$b_{w}$ & $\mathrm{~mm}$ & 52 & 175 & 123 & 35.74 & 0.28 \\
\hline$h_{f}$ & $\mathrm{~mm}$ & 39 & 105 & 58.78 & 19.69 & 0.35 \\
\hline$b_{f}$ & $\mathrm{~mm}$ & 153 & 918 & 419 & 182 & 0.48 \\
\hline$d$ & $\mathrm{~mm}$ & 175 & 354 & 232 & 39 & 0.14 \\
\hline$\rho_{l} f_{y l}$ & $\mathrm{MPa}$ & $5 . .69$ & 28.36 & 12.97 & 7.40 & 0.53 \\
\hline$b_{w} / d$ & Ratio & 0.23 & 0.82 & 0.54 & 0.14 & 0.32 \\
\hline$b_{f} / h_{f}$ & Ratio & 2.3 & 12.62 & 8.25 & 3.75 & 0.52 \\
\hline$\rho_{t} f_{y t}$ & $\mathrm{MPa}$ & 0 & 7.45 & 0.72 & 1.95 & 2.56 \\
\hline$a_{v} / d$ & Ratio & 2.48 & 10.39 & 4.35 & 1.65 & 0.42 \\
\hline$M_{f}$ & $\mathrm{kN}-\mathrm{mm}$ & 26998 & 407489 & 79278 & 75478 & 0.91 \\
\hline$V_{u}$ & $\mathrm{kN}$ & 18.8 & 81.45 & 40.43 & 15.89 & 0.35 \\
\hline \multicolumn{7}{|c|}{ Details of the Database TBWS } \\
\hline & & Min & Max & Mean & St. Dev & $\mathrm{COV}$ \\
\hline$f_{c}$ & $\mathrm{MPa}$ & 12 & 57 & 28.85 & 8.46 & 0.29 \\
\hline$b_{w}$ & $\mathrm{~mm}$ & 53 & 305 & 145 & 30.23 & 0.24 \\
\hline$h_{f}$ & $\mathrm{~mm}$ & 78 & 108 & 79.4 & 6.48 & 0.07 \\
\hline$b_{f}$ & $\mathrm{~mm}$ & 304 & 964 & 564 & 173.24 & 0.36 \\
\hline$d$ & $\mathrm{~mm}$ & 259 & 379 & 289 & 43.19 & 0.14 \\
\hline$\rho_{t} f_{y t}$ & $\mathrm{MPa}$ & 0 & 14.79 & 1.69 & 2.44 & 2.31 \\
\hline$b_{w} / d$ & Ratio & 0.145 & 1.45 & 0.55 & 0.13 & 0.27 \\
\hline$b_{f} / h_{f}$ & Ratio & 3.36 & 12.74 & 7.19 & 2.27 & 0.33 \\
\hline$\rho_{l} f_{y l}$ & $\mathrm{MPa}$ & 5.45 & 36.75 & 18.71 & 6.54 & 0.39 \\
\hline$\rho_{w} f_{y w}$ & $\mathrm{MPa}$ & 0.378 & 4.89 & 1.59 & 1.02 & 0.78 \\
\hline$a_{v} / d$ & Ratio & 1.54 & 7.35 & 3.86 & 1.82 & 0.22 \\
\hline$M_{f}$ & $\mathrm{kN}-\mathrm{mm}$ & 74358 & 407729 & 207263 & 90839 & 0.46 \\
\hline$V_{u}$ & $\mathrm{kN}$ & 72.69 & 378.5 & 167.59 & 74.58 & 0.43 \\
\hline
\end{tabular}

Figure 22a,b show $r$ for the input parameters with respect to the output parameters (i.e., $\mathrm{Vu}$ ) for TBWOS and TBWS. Based on these values, different combination of ANN models are proposed, as listed in Table 6.

Table 6. Architecture of ANN Models for TBWOS.

\begin{tabular}{cc}
\hline & Details of the Database for TBWOS \\
\hline VEXP & $b_{w}, h_{f}, b_{f}, d, f_{c}, \rho_{l} f_{y l}, a_{v} / d$, \\
TBWOS:01 & $b_{w}, h_{f}, b_{f}, d, f_{c}, \rho_{l} f_{y l}, a_{v} / d$, \\
TBWOS:02 & $b_{w}, h_{f}, b_{f}, f_{c}, M_{f} / f_{c} b_{w} d^{2}, a_{v} / d$, \\
TBWOS:03 & $b_{w} / d, b_{f} / h_{f}, \rho_{l} f_{y l}, f_{c} / f_{y l}, a_{v} / d$, \\
TBWOS:04 & $b_{w} / d, b_{f} / h_{f}, M_{f} / f_{c} b_{w} d^{2}, f_{c} / f_{y l}, a_{v} / d$, \\
\hline & Details of the Database for TBWS \\
\hline VEXP & $b_{w}, h_{f}, b_{f}, d, f_{c}, \rho_{l} f_{y l}, \rho_{w} f_{y w}, a_{v} / d$, \\
TBWS:01 & $b_{w}, h_{f}, b_{f}, d, f_{c}, \rho_{l} f_{y l}, \rho_{w w} f_{y w}, a_{v} / d$, \\
TBWS:02 & $b_{w}, h_{f}, b_{f}, d, f_{c}, M_{f} / f_{c} b_{w} d^{2}, \rho_{w} f_{y w}, a_{v} / d$, \\
TBWS:03 & $b_{w} / d, b_{f} / h_{f}, \rho_{v} f_{y v} / \rho_{l} f_{y l}, f_{c} / f_{y l}, a_{v} / d$, \\
TBWS:04 & $b_{w} / d, b_{f} / h_{f}, M_{f} / f_{c} b_{w} d^{2}, \rho_{w} f_{y w}, f_{c} / f_{y l}, a_{v} / d$, \\
\hline
\end{tabular}




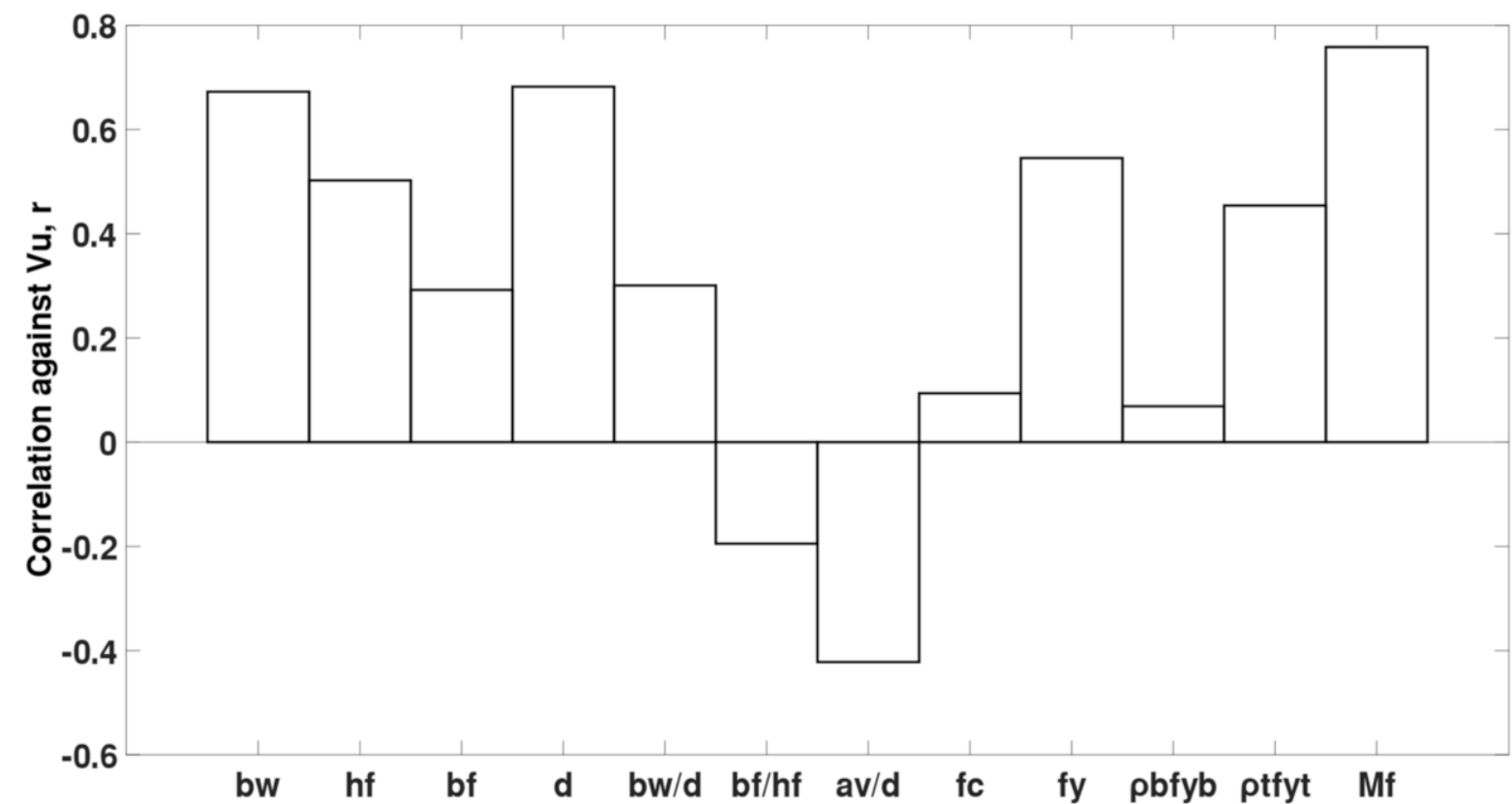

(a) TBWOS

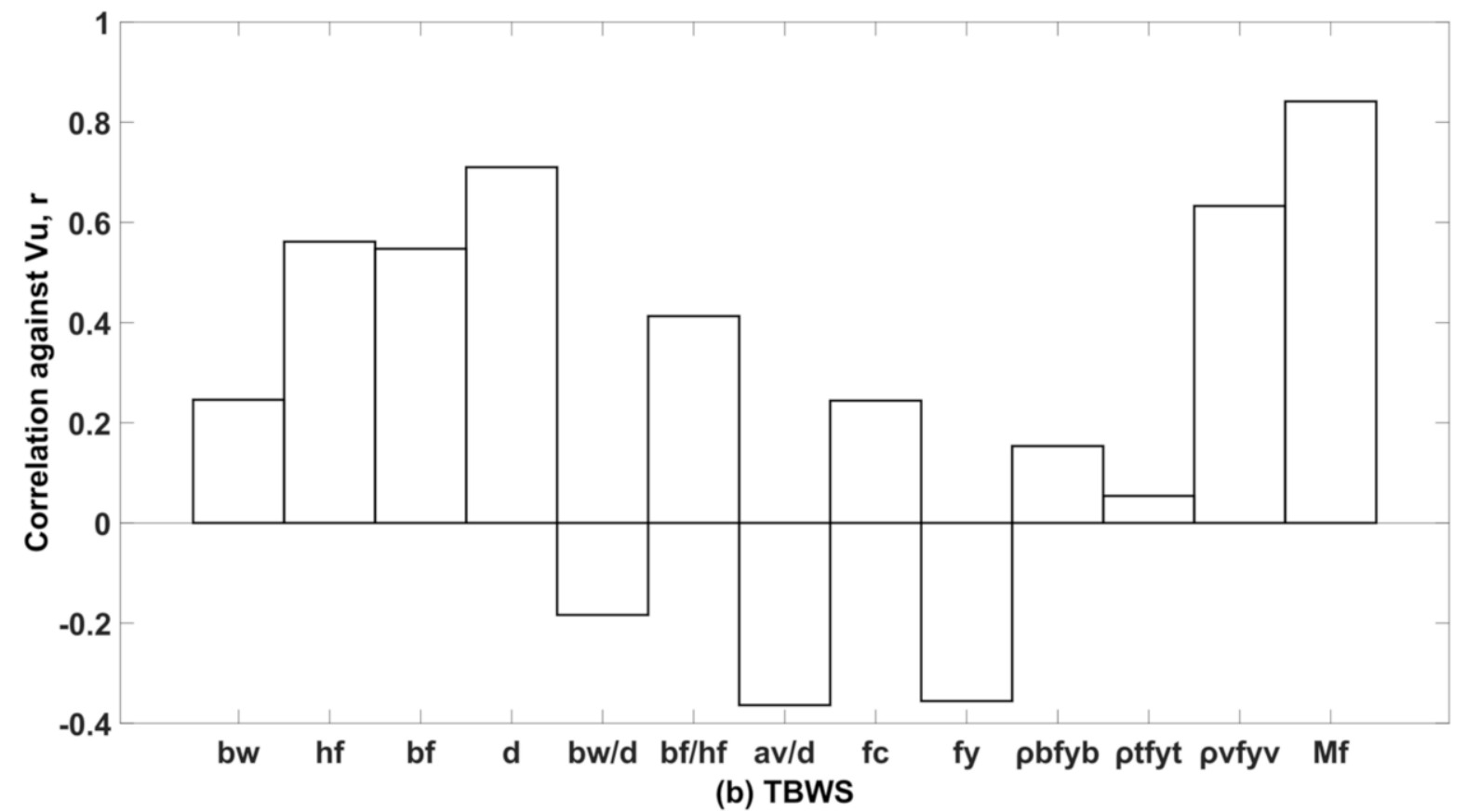

Figure 22. Correlation parameter $r$ values for (a) TBWOS and (b) TBWS.

\subsection{Development of ANN Models for DB-III}

Based on the $\mathrm{r}$ values, four different ANN models are proposed for the TBWOS and TBWS as discussed in Table 6. Based on Figures 23 and 24 TBWOS:02 (i.e., $b_{w}, d, f_{c}$, $M_{f} / f_{c} b_{w} d^{2}, h_{f}, b_{f}, a_{v} / d$ ) and TBWS: 03 (i.e., $b_{w} / d, \rho_{v} f_{y v} / \rho_{b} f_{y b}, f_{c} / f_{y}, b_{f} / h_{f}, a_{v} / d$, ) have higher $R$ value with lower MSE and MAE values. 

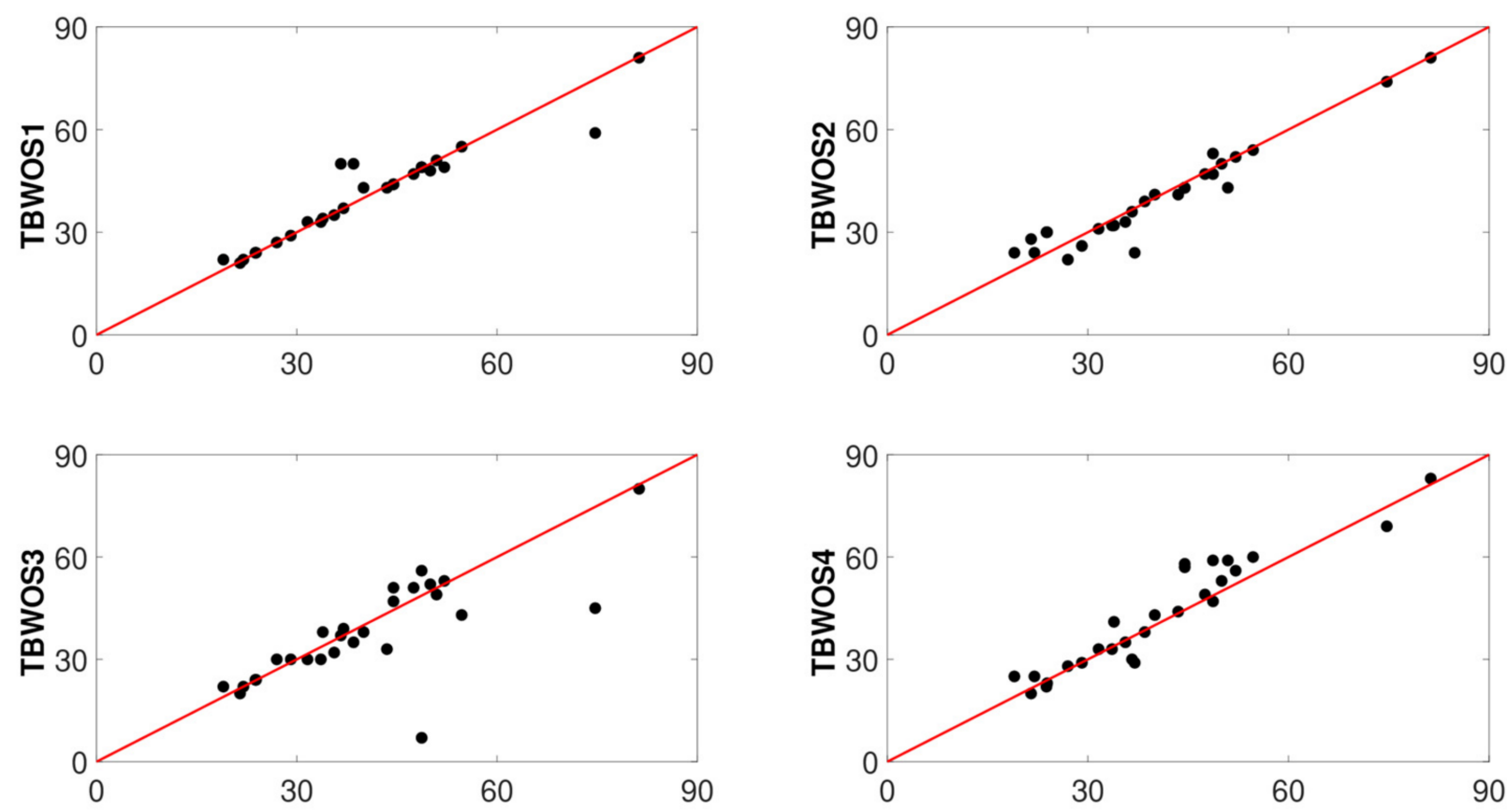

(a) TBWOS EXPERIMENTAL
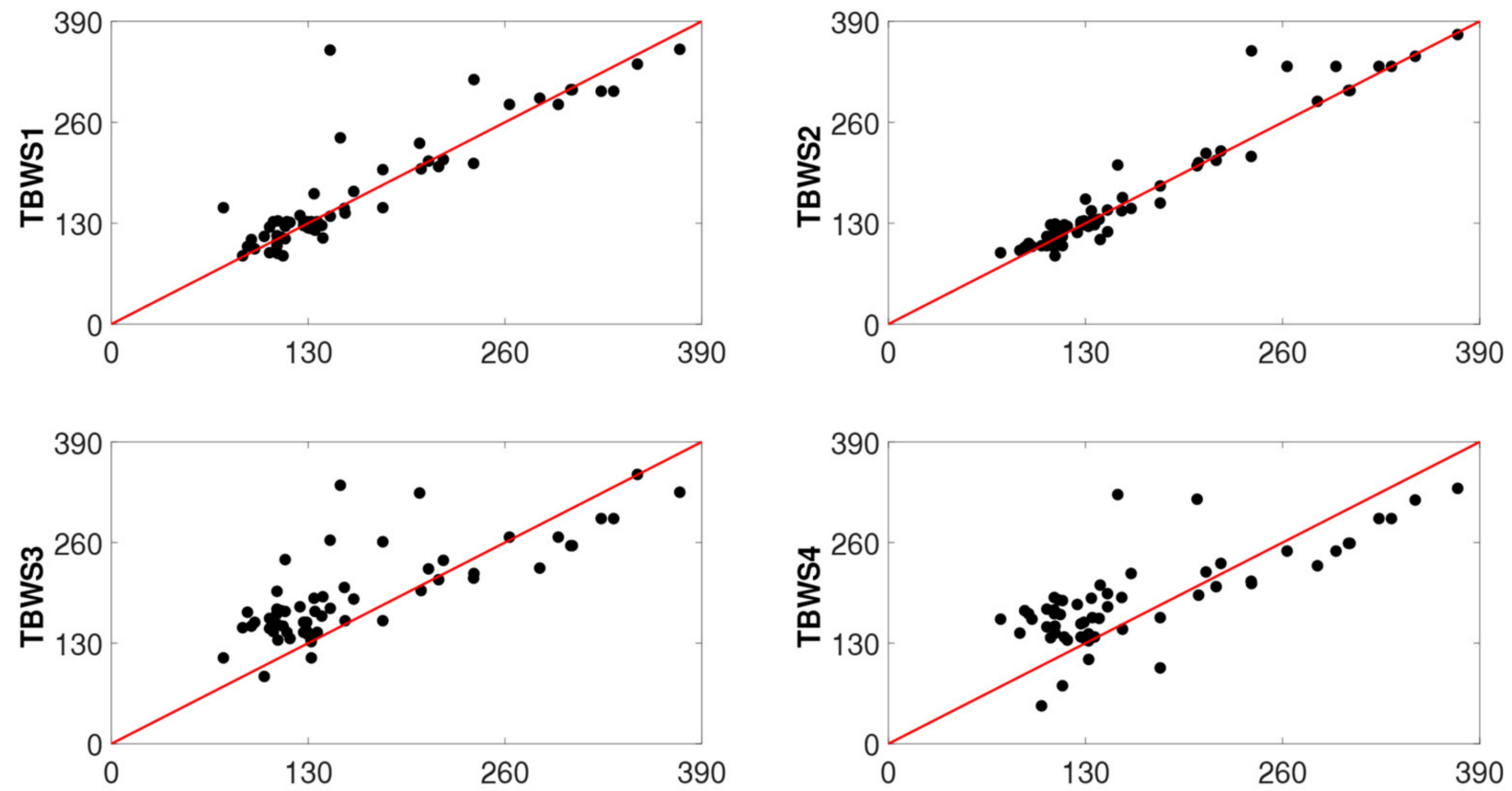

(b) TBWS EXPERIMENTAL

Figure 23. Predictions of ANN Models for (a) TBWOS and (b) TBWS. 

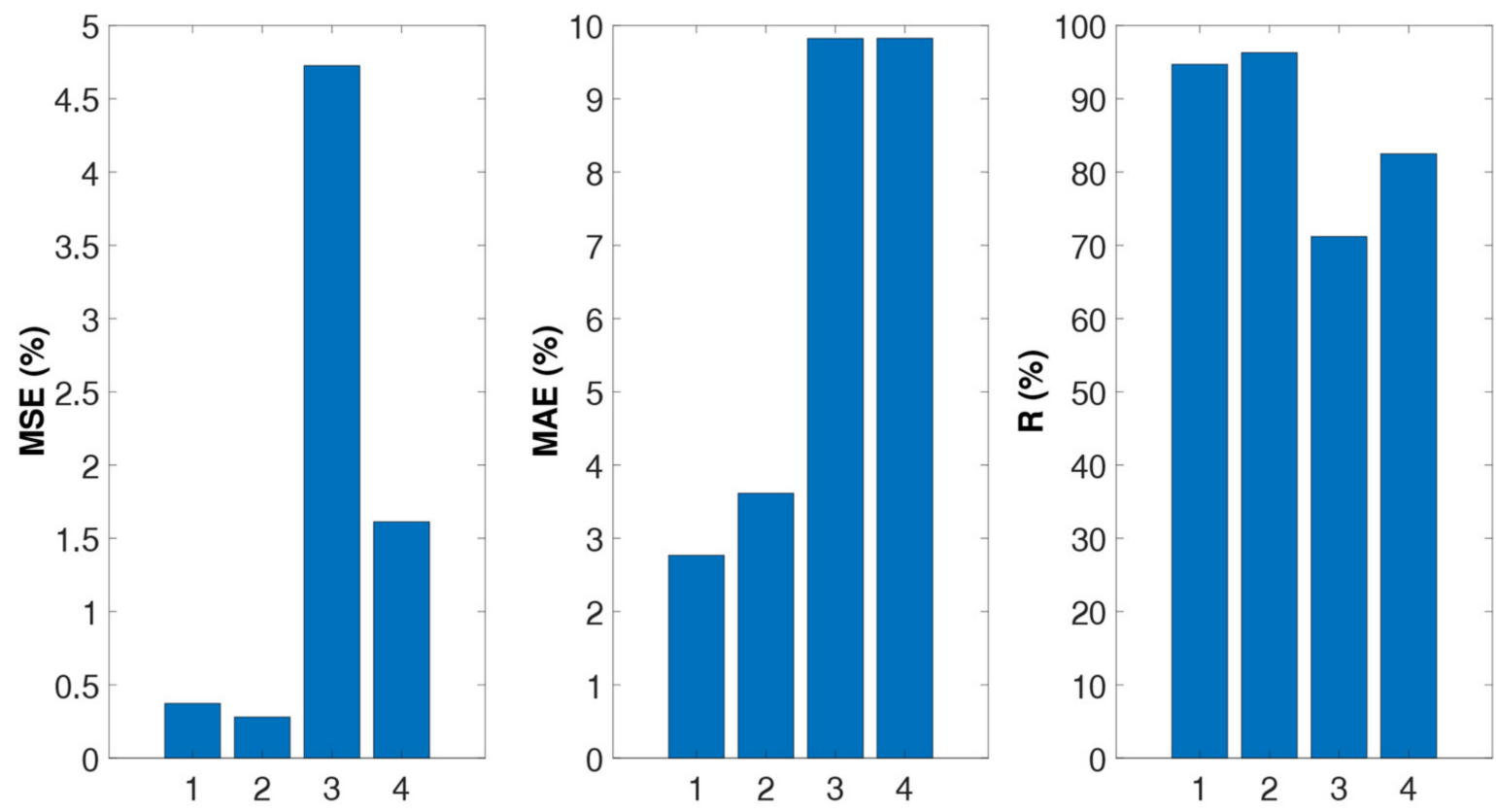

(a) TBWOS MODELS
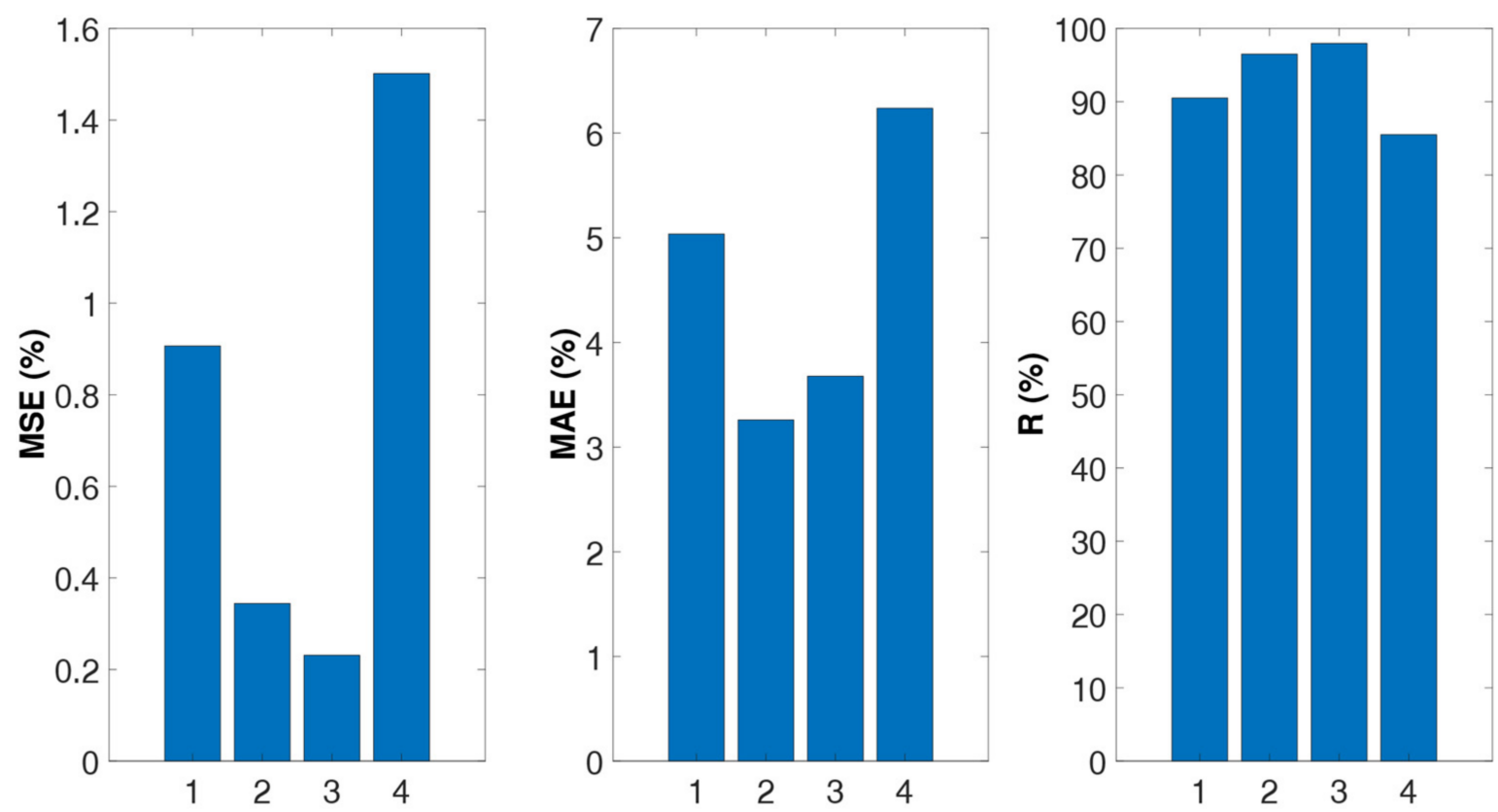

(b) TBWS MODELS

Figure 24. Error performance for (a) TBWOS and (b) TBWS.

\subsection{Comparative Studies for DB-III}

This section described the comparative study for above mentioned physical models for both TBWOS and TBWS. Figures 25-27 illustrate that the non-conventional models i.e.: ANN and the CFP method, are shown to be at least comparable to their counterparts CDC. Figure 26a,b present GD ratios indicating that ANN shows the best GD with the least (S. DEV), and a mean value is near to 1.05 , followed by the estimates obtained by the TBWOS CFP and TBWS. The other physical models' predictions mostly underestimate the predictions compared to the ANN models and CFP method. 

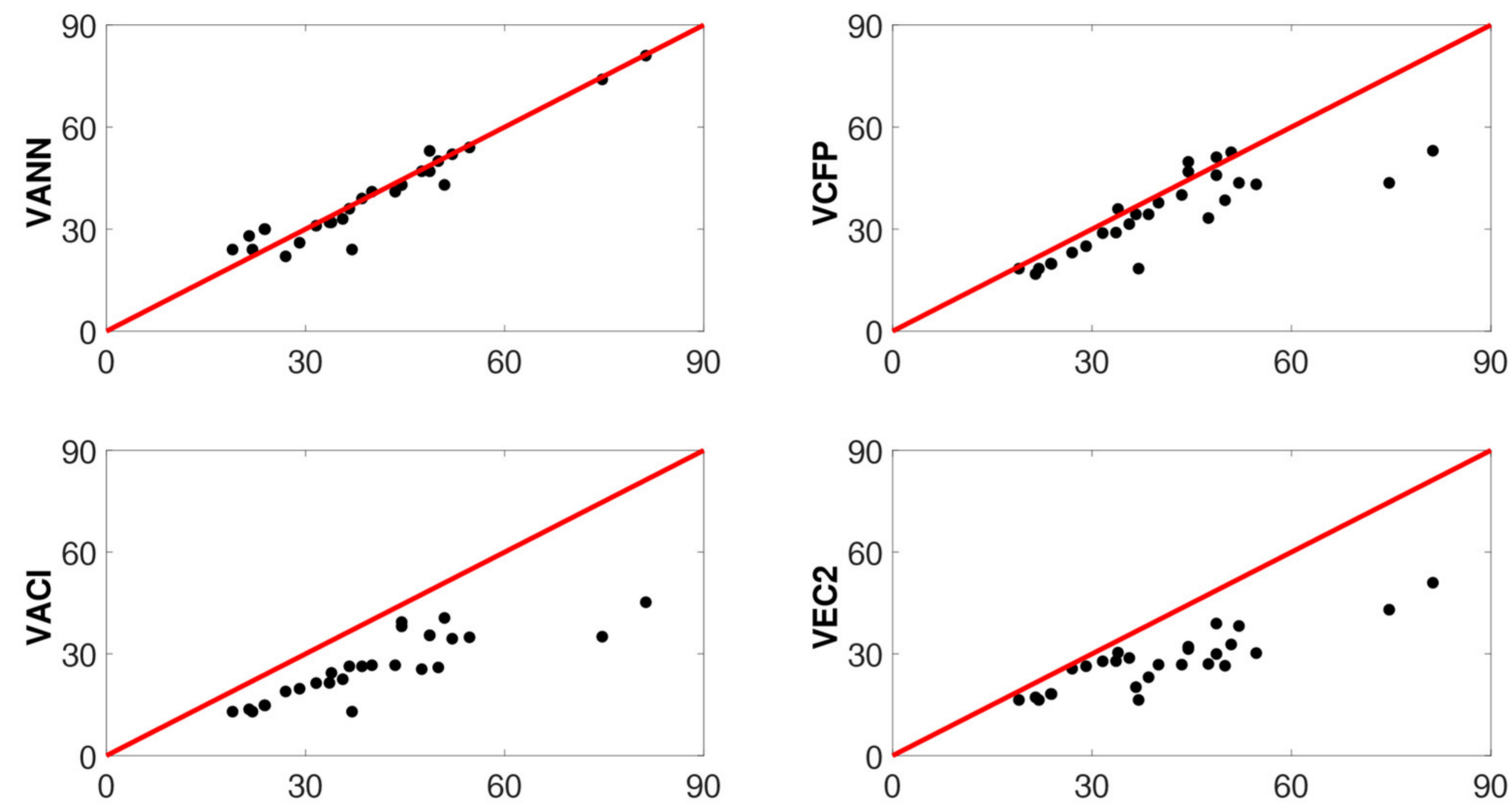

(a) TBWOS EXPERIMENTAL
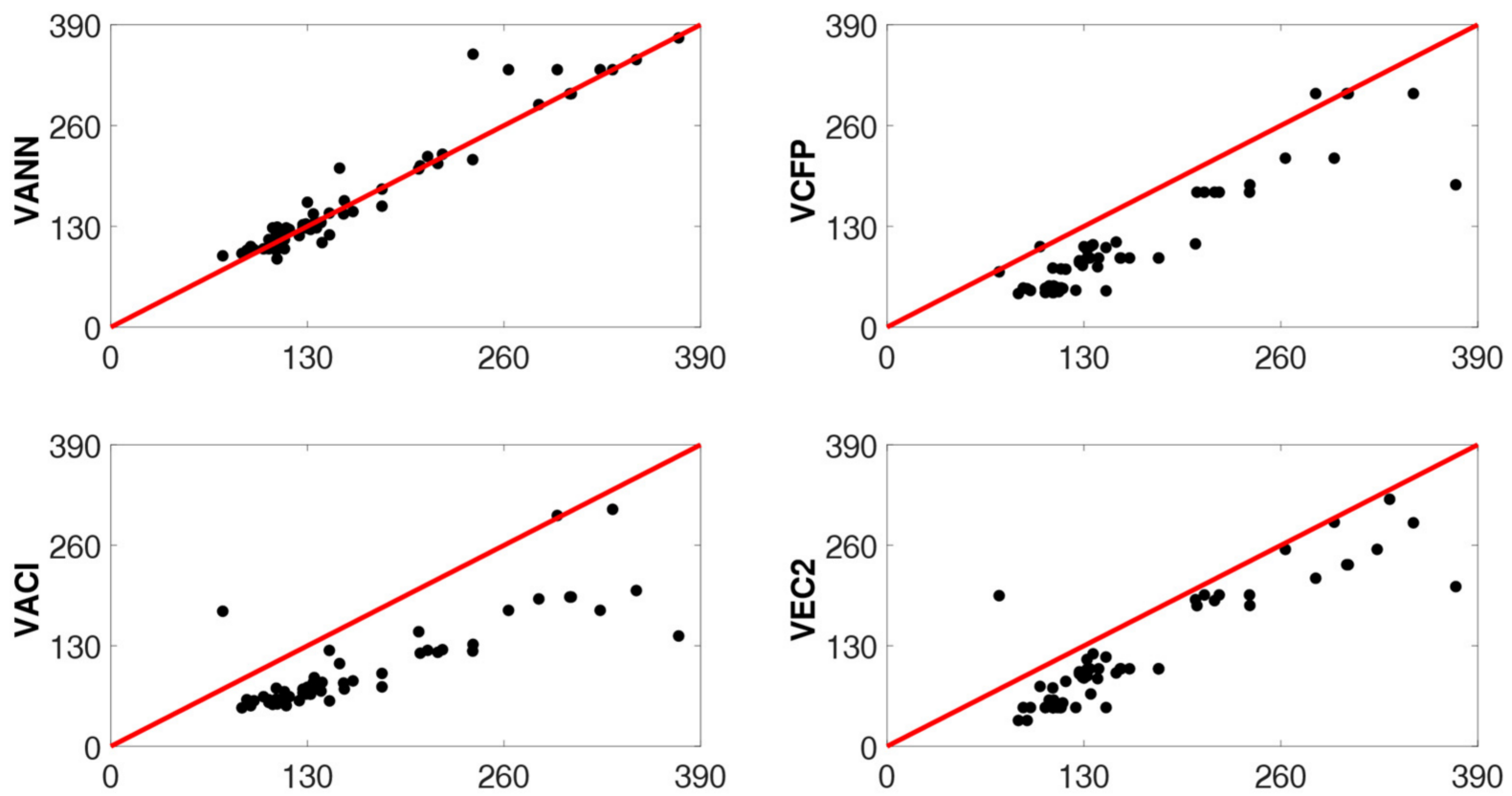

(b) TBWS EXPERIMENTAL

Figure 25. Comparative study for (a) TBWOS and (b) TBWS. 


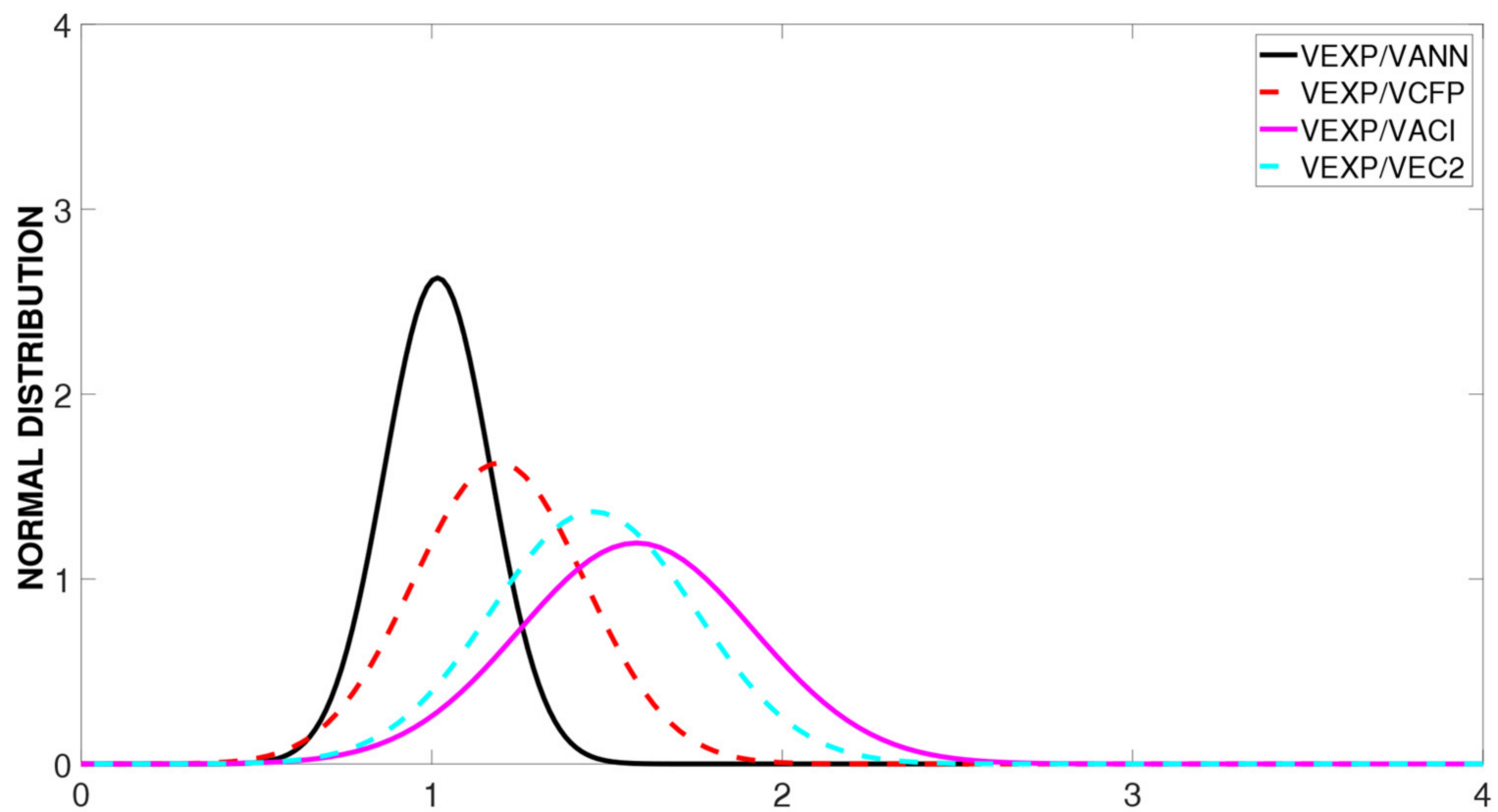

(a) TBWOS VEXP/VPRE

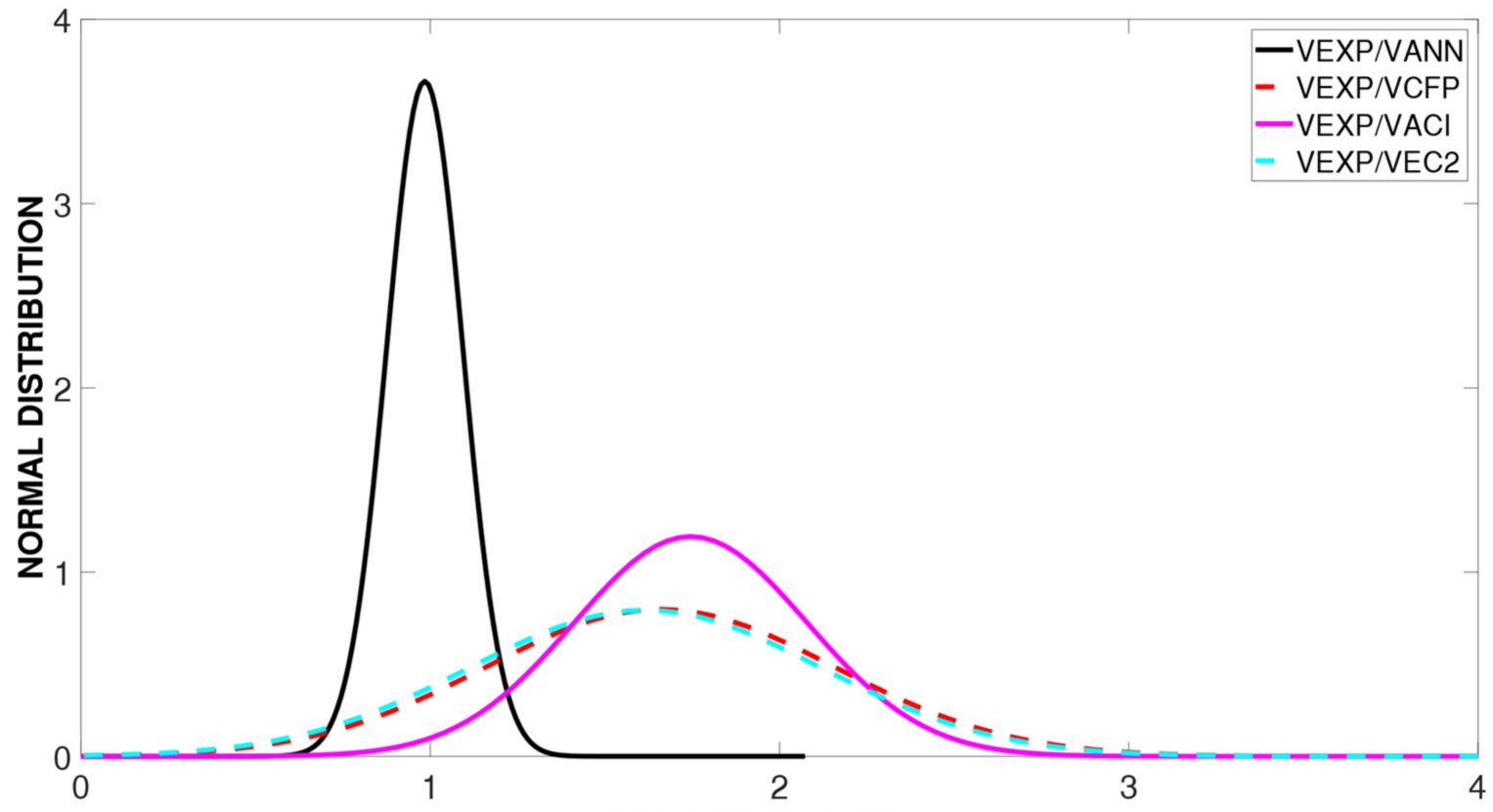

(b) TBWS VEXP/VPRE

Figure 26. Normal Distribution (a) TBWOS and (b) TBWS. 


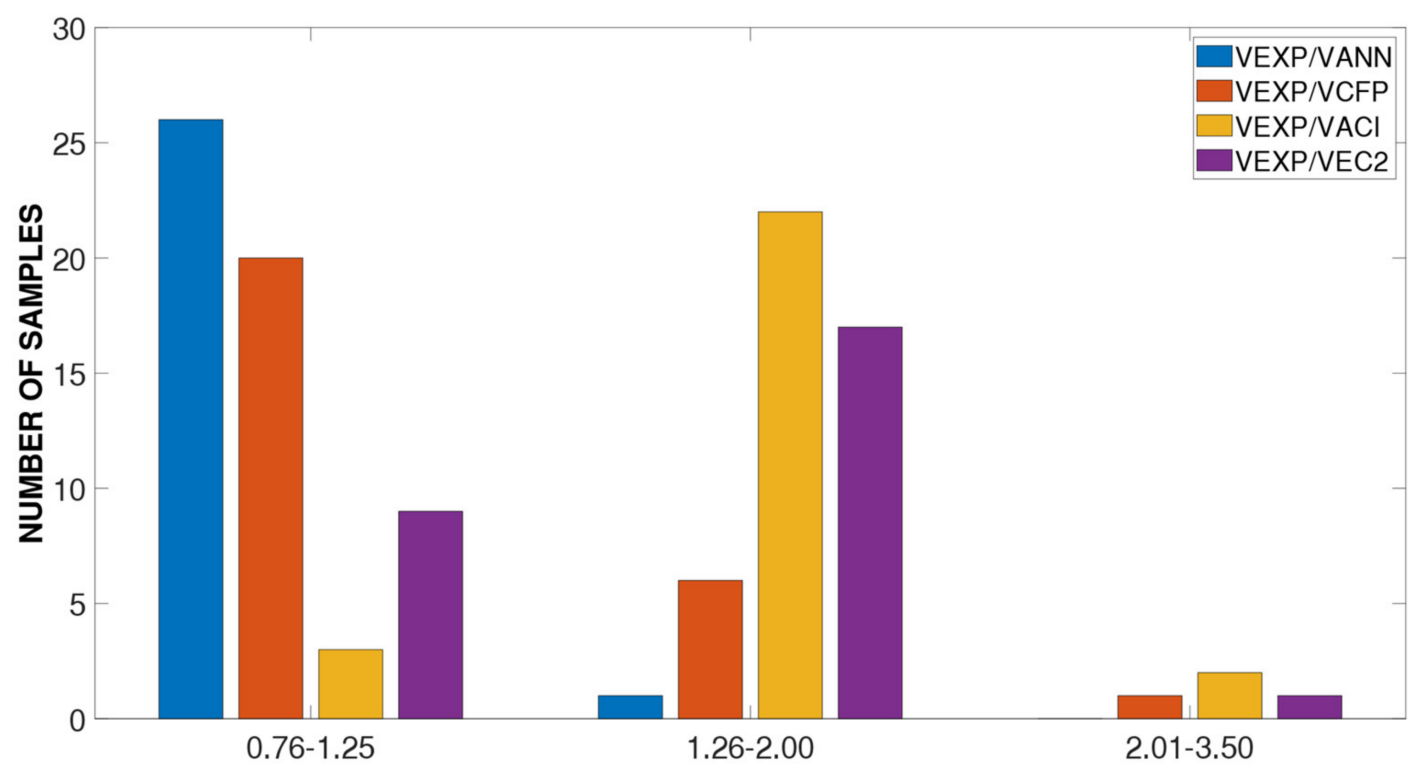

(a) TBWOS VEXP/VPRE

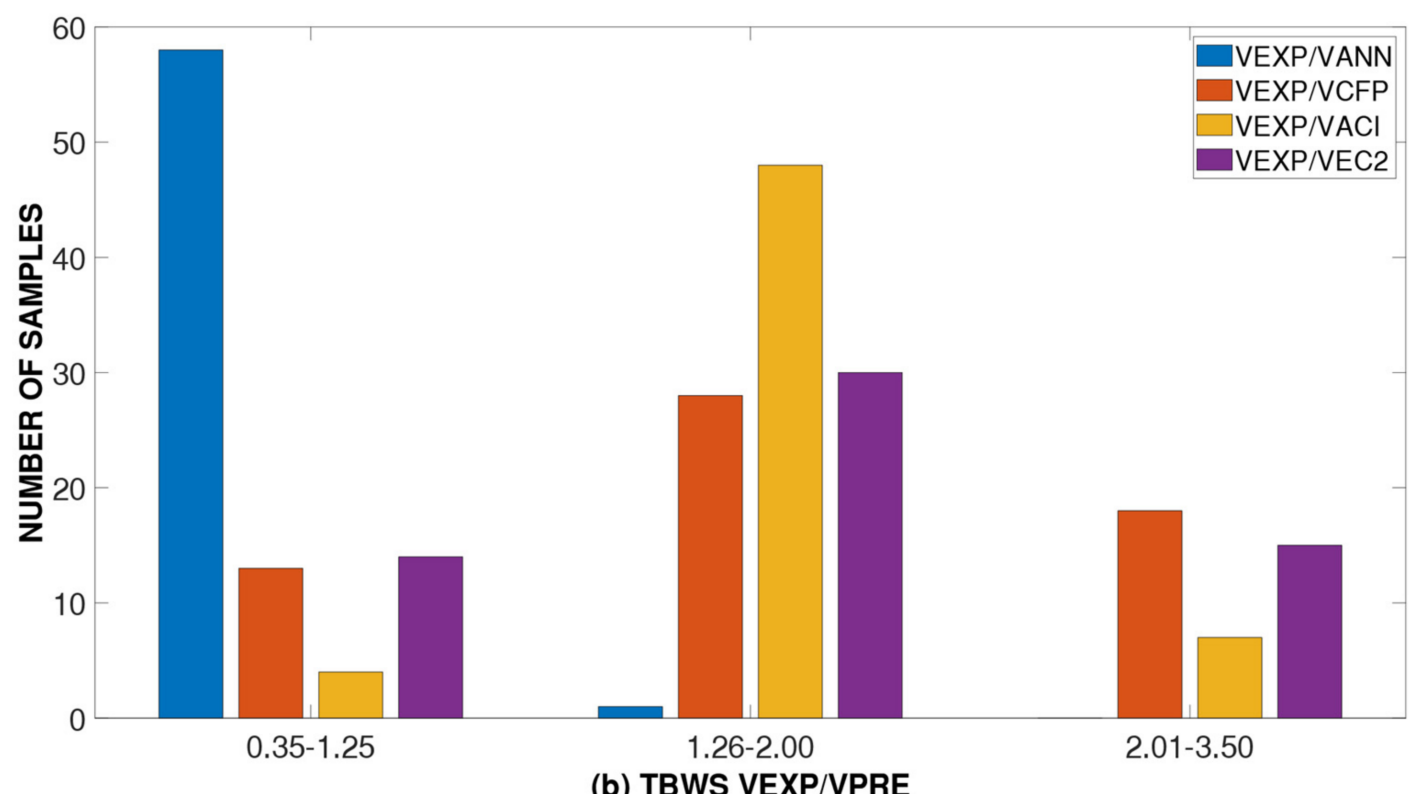

(b) TBWS VEXP/VPRE

Figure 27. Ratios distribution for (a) TBWOS and (b) TBWS.

Figure 27a,b reveal how much variation is in the overestimates or underestimates. Like the previous outcome, the ANN results for the case of TBWOS $80 \%$ of the results are in the region of 0.755 to 1.255 , i.e., accurate portion and $90 \%$ of the results for the case of TBWS. The other physical models' predictions mostly underestimate the predictions as related to the ANN models and CFP method.

\section{Database-IV: SCS}

The fourth database (DB-IV) includes 145 samples of flat RC flats slab (SCS) as shown in Figure 28 to find their punching strength. Table 7 provides information about the critical parameter as illustrated in Figure 25. 99\% of the samples (i.e., 143) failed in a shear manner while the remainder failed in a flexural manner. Figure 29 shows the histogram for the critical parameters for the SCS. This histogram describes the frequency of the parameters 
against the different sample values. This is also a limitation of ANN models, as they will predict against these limits of each parameter.

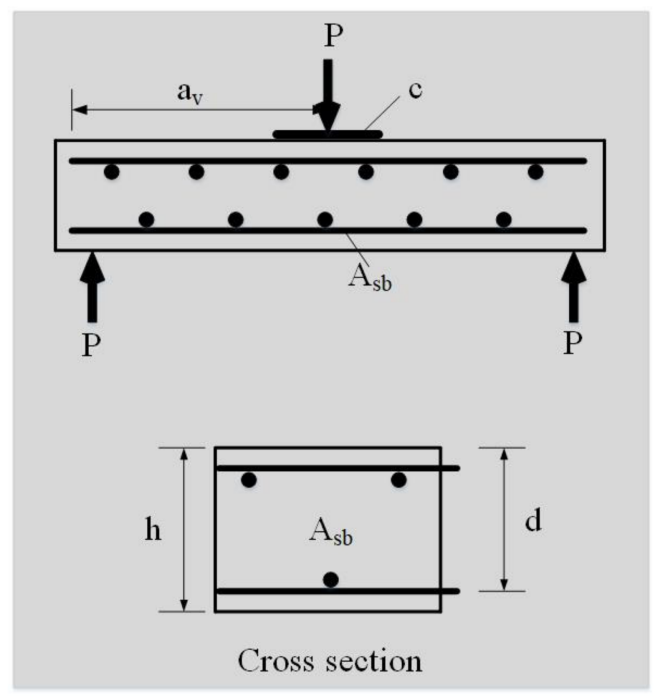

Figure 28. Experimental setup for SCS.

Table 7. Database information for RC Flat Slab.

\begin{tabular}{ccccccccc}
\hline & $\mathbf{c}$ & $\mathbf{d}$ & $\boldsymbol{\alpha v} / \mathbf{d}$ & $\mathbf{\rho l}$ & $\mathbf{f y l}$ & $\mathbf{f c}$ & $\mathbf{M f}$ & $\mathbf{V u}$ \\
\hline & $\mathbf{( m m )}$ & $\mathbf{( m m )}$ & & $\mathbf{( \% )}$ & $\mathbf{( M P a )}$ & $\mathbf{( M P a )}$ & $\mathbf{k N}-\mathbf{m m}$ & $\mathbf{( k N )}$ \\
\hline Min & 54 & 64 & 4.5 & 0.3 & 294 & 9.52 & 39,000 & 105 \\
Max & 600 & 275 & 14.02 & 6.9 & 749 & 118.7 & $1,951,000$ & 2450 \\
Avg. & 206.34 & 122.32 & 7.81 & 1.31 & 496.88 & 41.3 & 252,655 & 458.7 \\
St. Dev & 87 & 44.82 & 2.4 & 0.89 & 117.68 & 24.85 & 292,121 & 436.88 \\
COV & 0.42 & 0.37 & 0.31 & 0.68 & 0.24 & 0.6 & 1.16 & 0.95 \\
\hline
\end{tabular}
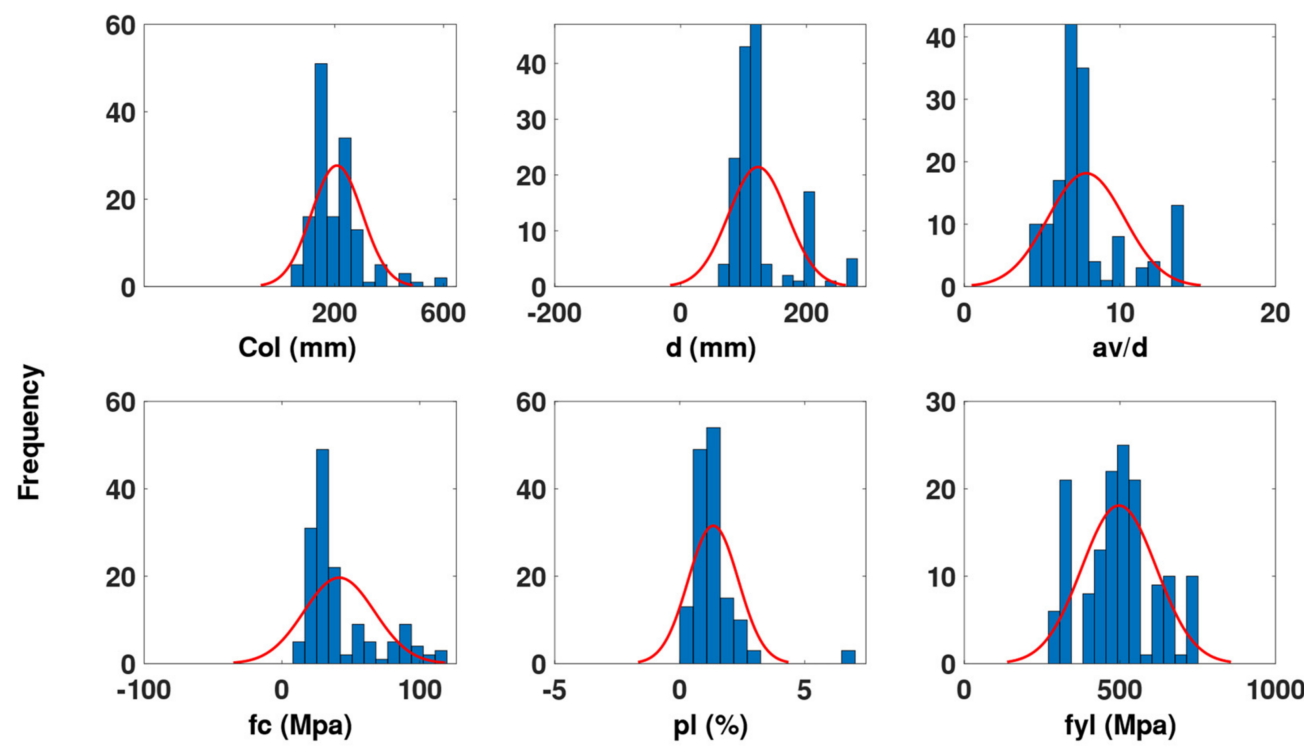

Figure 29. Histogram of the critical Parameters for RC Flat Slab.

Figure 30 provides the $\mathrm{r}$ values, which suggest the different ANN models comprising different possible combinations of input parameters for RC flat slabs as discussed in Table 8 . 


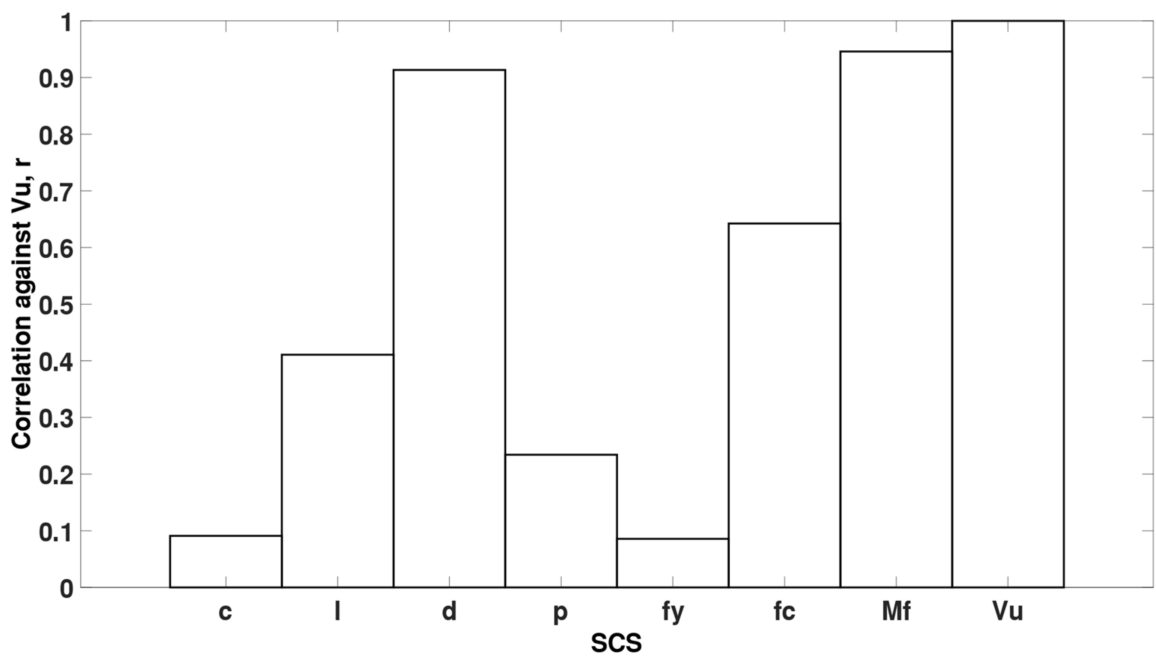

Figure 30. Correlation values $\mathrm{r}$ for SCS.

Table 8. Proposed models for ANN.

\begin{tabular}{cc}
\hline Model & Parameters \\
\hline SCS:01 & $c, d, \rho_{l}, f_{y l}, f_{c}, a_{v} / d$, \\
SCS:02 & $c, d, M_{f}, f_{c}, a_{v} / d$, \\
SCS:03 & $c / d, M_{f} / f_{c} b d^{2}, a_{v} / d$, \\
SCS:04 & $c / d, \rho_{l}, f_{c} / f_{y l}, a_{v} / d$, \\
SCS:05 & $d, M_{f} / b d^{2}, f_{c}, a_{v} / d$, \\
SCS:06 & $d, c / d, M_{f} / f_{c} b d^{2}, a_{v} / d$, \\
SCS:07 & $d, c / d, M_{f} / f_{c} b d^{2}, f_{c}, a_{v} / d$, \\
\hline
\end{tabular}

\subsection{Development of ANN Models for DB-IV}

Based on the $\mathrm{r}$ value, seven different ANN models are proposed for SCS based on Figure 30. Table 8 describes these parameter combinations based on the CDCs assumption.

Based on Figures 31 and 32 SCS:4 $\left(c / d, a_{v} / d, \rho_{p} l_{f_{c}} / f_{y}\right)$ is the best model as it exhibits the maximum value of $R$ while at the same time showing the minimum values of MSE and MAE.
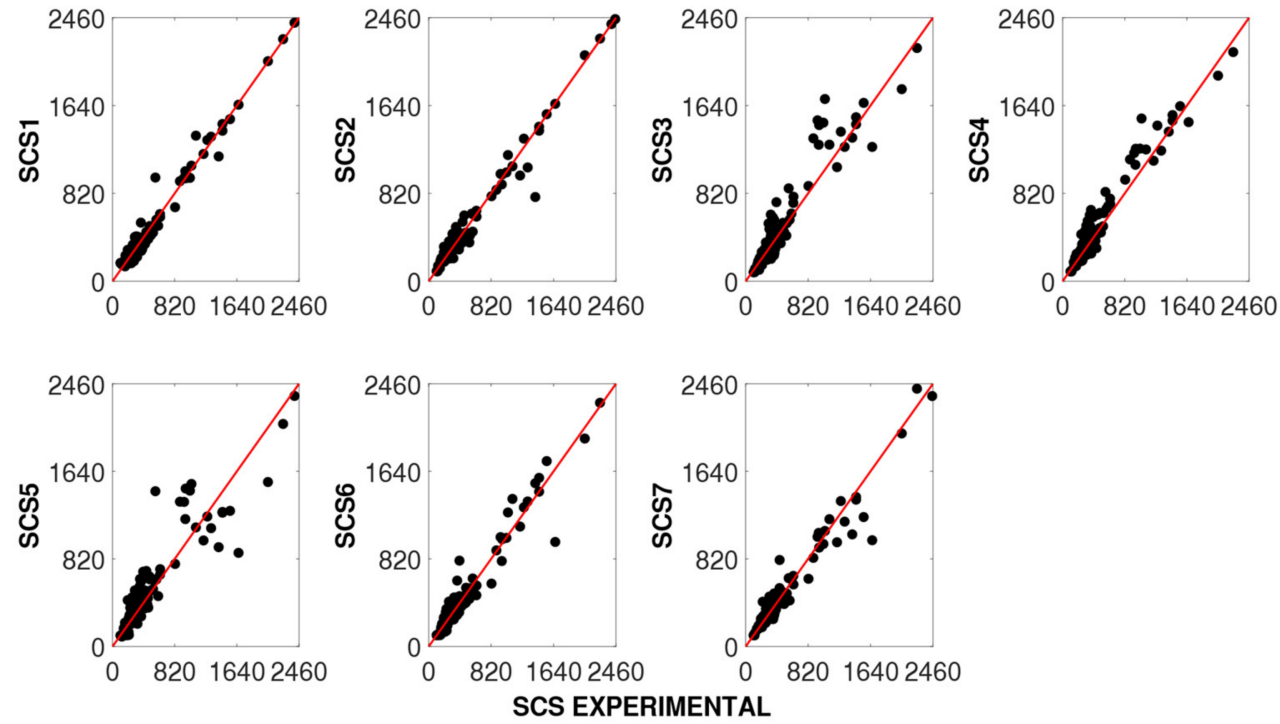

Figure 31. ANN models for the case of SCS. 

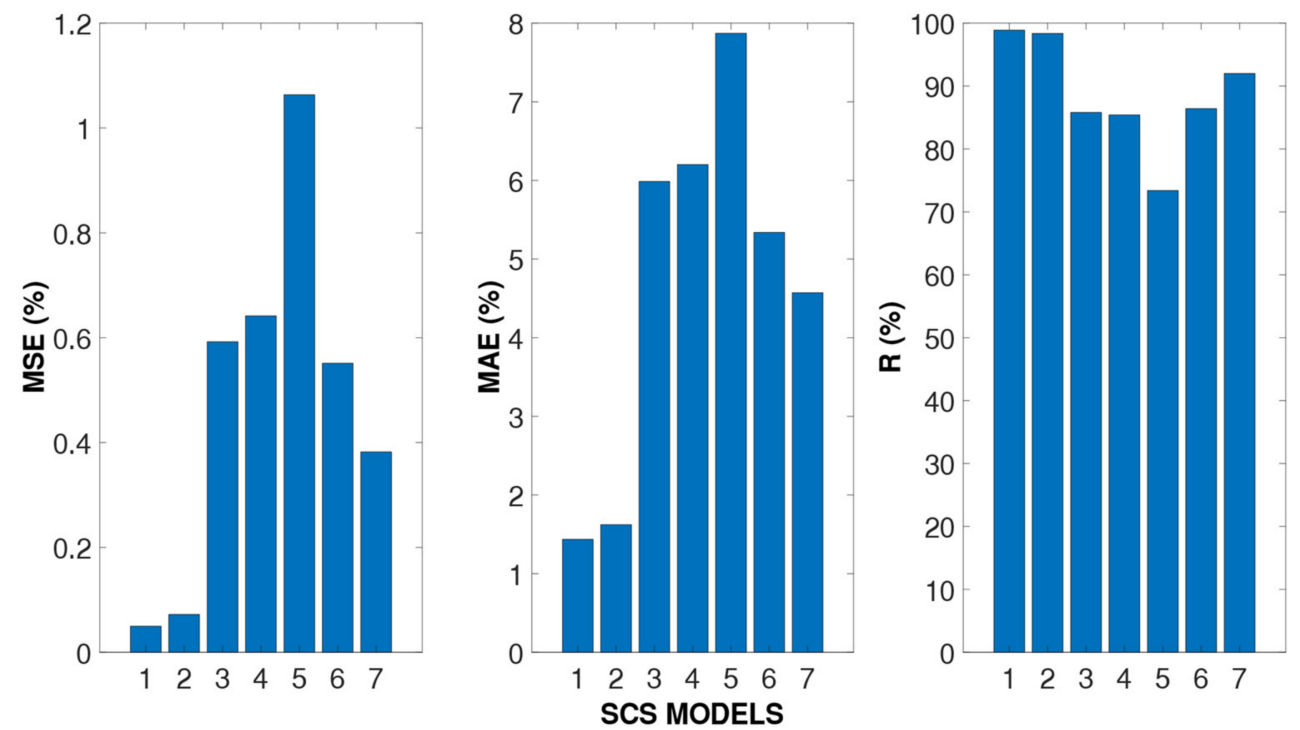

Figure 32. Error Performance for SCS.

\subsection{Comparative Studies for DB-IV}

This section discusses a comparative study between the abovementioned physical model-predicted ANN, the CFP method [53,54] and the CDCs $[1,2]$ as presented in Figures 33-35 for SCS.
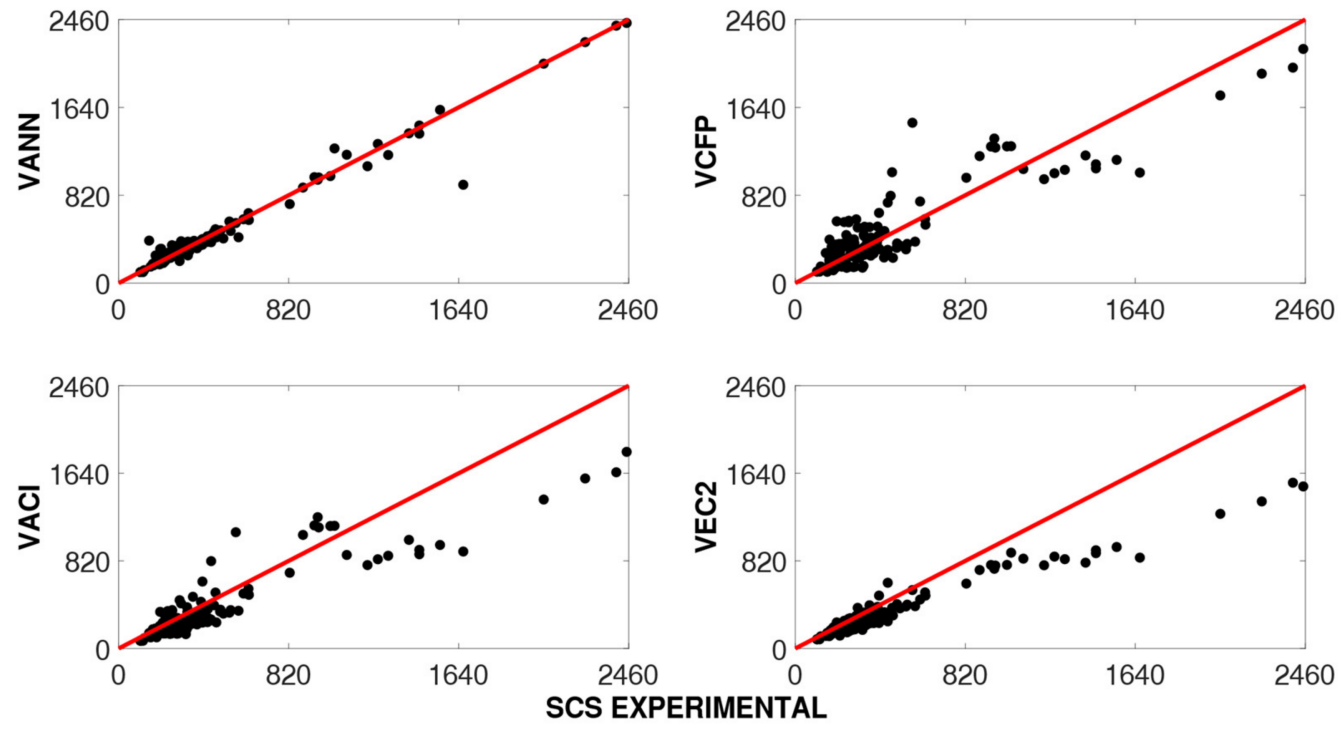

Figure 33. Comparative study for SCS.

Figure 34 presents the GD of the ratios, showing that the ANN exhibits the least S. DEV of 1.05 , followed by the CFP. The other physical models' results most underestimate the predictions compared to the ANN models and CFP method.

Figure 35 reveals the overestimation and underestimation values for ULS. Like the previous outcome, the $\mathrm{CDCs}$ (i.e., $\mathrm{ACI}$ and EC2) are mostly lower than the provided results, where the $90 \%$ of the results of the non-conventional models i.e.: ANN and CFP are in the accurate region i.e.: 0.755 to 1.255 . The other physical models' predictions mostly underestimate the predictions compared to the ANN models and CFP method. 


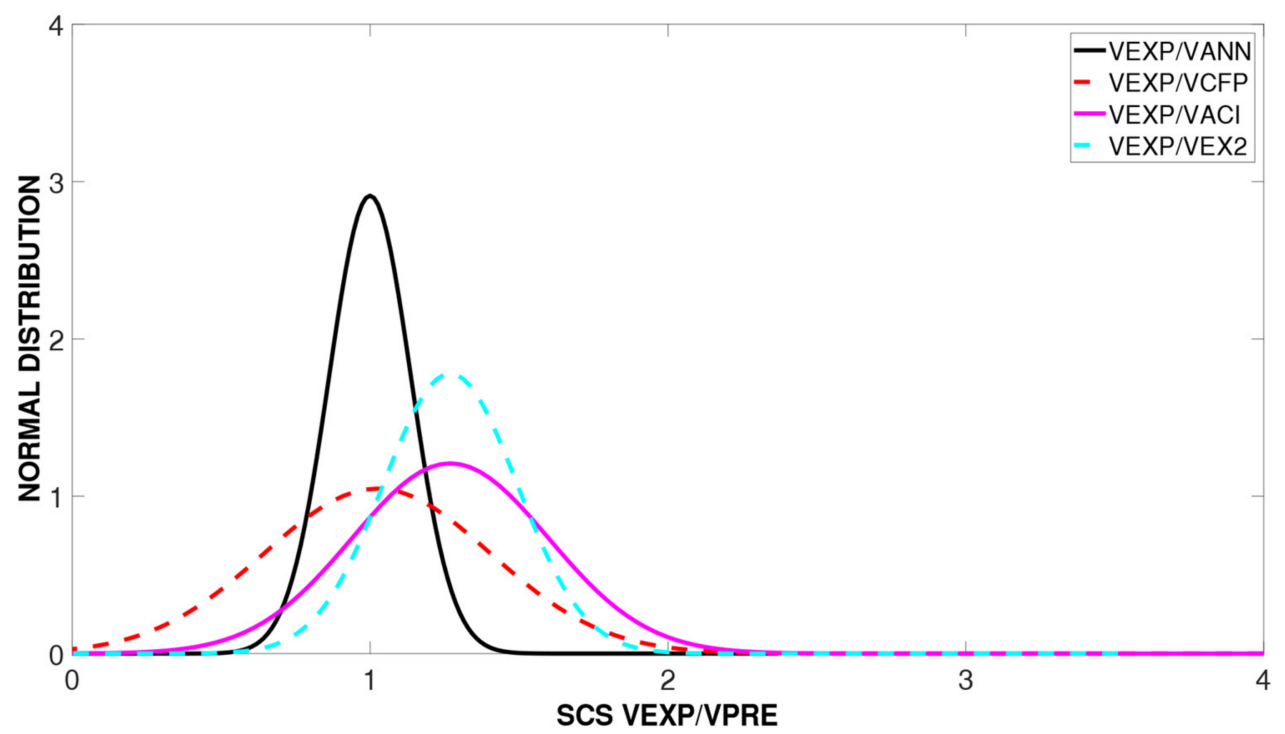

Figure 34. Normal Distribution for SCS.

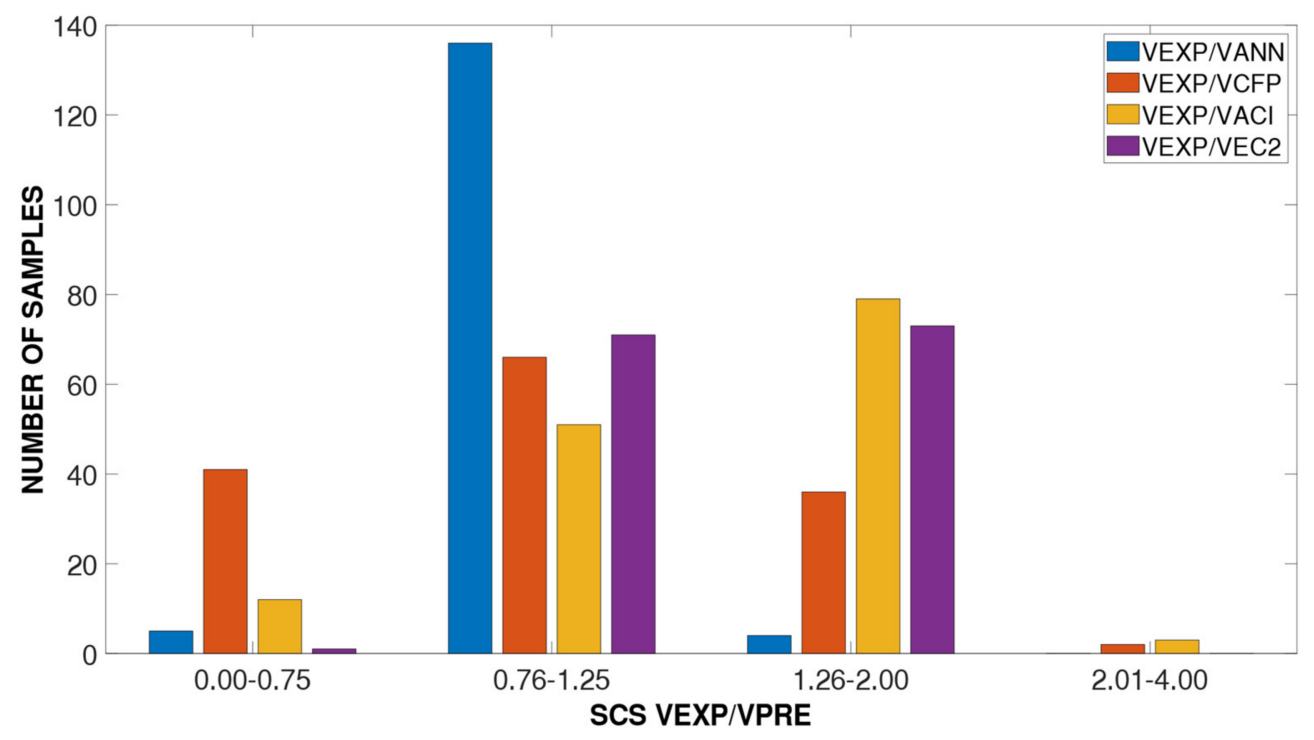

Figure 35. Ratio Distribution for SCS.

\section{Conclusions}

The work describes the applicability of ANN modelling to simple and complex RC members under different loading conditions i.e.: (i) RC beams in simply supported condition without transverse steel or stirrups (BWOS) and RC beams in simply supported condition with transverse steel or stirrups (BWS), (ii) RC columns in cantilever supported conditions (CWA), (iii) RC T-beams in simply supported conditions without transverse steel or stirrups (TBWOS) and RC T-beams in simply supported condition with transverse steel or stirrups (TBWS) and (iv) RC flat slabs in simply supported condition under a punching load (SCS). The optimized ANN model among the other ANN models is selected based on the corresponding $\mathrm{R}$ value. The $\mathrm{R}$ value of the BWOS-4 (i.e., $d, M_{f} / b d^{2}, f_{c}, a_{v} / d$ ) is $97 \%$, for BWS-7 (i.e., $d, b / d, M f / f_{c} b d^{2}, f_{c}, \rho w, f_{y w}, a_{v} / d$ ) it is $98 \%$, for CWA-3 (i.e., $b / d, N / b d f_{c}$, $M f / f_{c} b d^{2}, \rho_{w}, f_{y w}, a_{v} / d$, ) it is $97 \%$, for TBWOS:02 (i.e., $b_{w}, d, f_{c}, M_{f} / f_{c} b_{w} d^{2}, h_{f}, b_{f}, a_{v} / d$, ) it is 97\%, for TBWS: 03 (i.e., $\left.b_{w} / d, \rho_{v} f_{y v} / \rho_{b} f_{y b}, f_{c} / f_{y}, b_{f} / h_{f}, a_{v} / d\right)$ it is $98 \%$ and for SCS: $4\left(c / d, a_{v} / d\right.$, $\left.\rho_{p} l, f_{c} / f_{y}\right)$ it is $97 \%$ for optimized models among the other ANN models. A comparative study showed the predictions of non-conventional models, i.e.: ANN models, are closer to the provided experimental values related to the other physical models i.e., CFP and CDCs. 
This result is similar to the results of other researchers [55-59] working on the different databases. Unlike the conventional methodology, soft computing techniques like ANN models have the capabilities to predict the response of RC members with simple or complex geometry under different loading conditions. Once the ANNs are trained on the provided database, they can provide an accurate prediction without concerning material behavior and the mechanics underlying the RC structural response at ULS. The comparative study conducted between the predicted values for the RC members concerning the ultimate response shows the results from the ANN are close to CFP and EC-2 and more accurate as compared to those obtained from the ACI Code.

\section{Future Directions of the Current Work}

These ANN models can be used along with professional design software during the non-linear static analysis process, to predict the ultimate limit response of RC members under complex loading requiring analysis times and providing accurate results as compare to the CDCs. The authors are working on this direction and have achieved acceptable results that will be reported in due course.

Author Contributions: The Conceptualization, A.A. and D.M.C., methodology, N.D.L. and software, A.A. and N.D.L.; validation, A.A. and D.M.C. data curation, D.M.C., writing-original draft preparation, A.A. and N.D.L. Authorship must be limited to those who have contributed substantially to the work reported. All authors have read and agreed to the published version of the manuscript.

Funding: This research received no external funding.

Institutional Review Board Statement: Not applicable.

Informed Consent Statement: Not applicable.

Data Availability Statement: The details of all database will be published after completion of the on-going research by using MDPI data journal.

Acknowledgments: Not applicable.

Conflicts of Interest: The authors declare no conflict of interest.

\section{References}

1. EC2. Eurocode 2: Design of Concrete Structures-Part 1-1: General Rules And Rules For Buildings. In EN 1992-1-1; Management Centre: Brussels, Belgium, 2004.

2. ACI. Building Code Requirements for Structural Concrete (ACI 318-08) and Commentary. In Aci-318-08; American Concrete Institute: Farmington Hills, MI, USA, 2008; pp. 1-471.

3. JSCE. Standard Specifications for Concrete Structures-2007. In JSCE Guideline for Concrete No. 15; JSCE: Tokyo, Japan, 2007; pp. 1-503.

4. CSA. Design of Concrete Structures. In A23.3-04; CSA: Mississauga, ON, Canada, 2004; pp. 1-232.

5. NZS. Concrete Structures Standard Part-1. In NZS 3101; New Zealand Standard: Wellington, New Zealand, 2006; Volume Part 1, pp. 1-309.

6. KBCS. Korean Building Code-Structural (KBCS); Architectural Institute of Korea: Kimoondang, Korea, 2005.

7. T. S. SarmaSTAAD. Pro V8i; Bentley Systems, Inc.: Exton, PA, USA, 2008; Volume 8.

8. CSI Group. SACS Import Manual; Computers and Structures Inc.: Berkeley, CA, USA, 2013.

9. Ahmad, A.; Kotsovou, G.; Cotsovos, D.M.; Lagaros, N.D. Assessing the accuracy of RC design code predictions through the use of artificial neural networks. Int. J. Adv. Struct. Eng. 2018, 10, 349-365. [CrossRef]

10. Ahmad, A.; Cotsovos, D.M.; Lagaros, N.D. Framework for the development of artificial neural networks for predicting the load carrying capacity of RC members. SN Appl. Sci. 2020, 2, 1-21. [CrossRef]

11. Ahmad, A.; Cotsovos, D.M. Reliability analysis of models for predicting T-beam response at ultimate limit response. Proc. Inst. Civ. Eng. Struct. Build. 2020, 1-23. [CrossRef]

12. Kotsovou, G.M.; Ahmad, A.; Cotsovos, D.M.; Lagaros, N.D. Reappraisal of methods for calculating flexural capacity of reinforced concrete members. Proc. Inst. Civ. Eng. Struct. Build. 2020, 173, 279-290. [CrossRef]

13. Ahmad, A. Reinforced Concrete (RC) Structures Analysis and Assessment with Artificial Neural Networks (ANNs); Heriot-Watt University: Edinburgh, Scotland, 2018.

14. Kotsovos, M.D. Compressive Force-Path Method; Springer: Berlin/Heidelberg, Germany, 2013. 
15. Papadrakakis, M.; Lagaros, N.D. Reliability-based structural optimization using neural networks and Monte Carlo simulation. Comput. Methods Appl. Mech. Eng. 2002, 191, 3491-3507. [CrossRef]

16. Lagaros, N.D.; Papadrakakis, M. Learning improvement of neural networks used in structural optimization. Adv. Eng. Softw. 2004, 35, 9-25. [CrossRef]

17. Lagaros, N.D.; Charmpis, D.C.; Papadrakakis, M. An adaptive neural network strategy for improving the computational performance of evolutionary structural optimization. Comput. Methods Appl. Mech. Eng. 2005, 194, 3374-3393. [CrossRef]

18. Lagaros, N.D.; Plevris, V.; Papadrakakis, M. Multi-objective design optimization using cascade evolutionary computations. Comput. Methods Appl. Mech. Eng. 2005, 194, 3496-3515. [CrossRef]

19. Lagaros, N.D.; Fragiadakis, M. Fragility assessment of steel frames using neural networks. Earthq. Spectra 2007, 23, 735-752. [CrossRef]

20. Ahmad, A.; Plevris, V.; Khan, Q.-U.-Z. Prediction of Properties of FRP-Confined Concrete Cylinders Based on Artificial Neural Networks. Crystals 2020, 10, 811. [CrossRef]

21. Almuhaylan, M.R.; Ghumman, A.R.; Al-Salamah, I.S.; Ahmad, A.; Ghazaw, Y.M.; Haider, H.; Shafiquzzaman, M.J.W. Evaluating the Impacts of Pumping on Aquifer Depletion in Arid Regions Using MODFLOW, ANFIS and ANN. Water 2020, $12,2297$. [CrossRef]

22. Iqbal, M.; Naeem, U.A.; Ahmad, A.; Ghani, U.; Farid, T.J.M. Relating groundwater levels with meteorological parameters using ANN technique. Measurement 2020, 166, 108163. [CrossRef]

23. Raza, A.; Khan, Q.U.Z.; Ahmad, A. Prediction of axial compressive strength for FRP-confined concrete compression members. Ksce J. Civ. Eng. 2020, 24, 2099-2109. [CrossRef]

24. Manfredi, V.; Masi, A.; Nicodemo, G.; Digrisolo, A.; Santarsiero, G. The Role of Damage Extent in the Estimation of Direct Economic Losses of Existing RC Buildings; Pisa University Press: PISA, Italy, 2019; pp. 36-45.

25. Nigro, D.; Digrisolo, A.; Ventura, G.; Santarsiero, G.; Masi, A.; Manfredi, V. Development of Integrated Techniques to Improve Seismic Performance and Energy Efficiency of Buildings: Preliminary Results of the Experimental Campaign on RC Portal Frames; Pisa University Press: PISA, Italy, 2019; pp. 128-137.

26. Shakya, A.; Mishra, M.; Maity, D.; Santarsiero, G. Structural health monitoring based on the hybrid ant colony algorithm by using Hooke-Jeeves pattern search. SN Appl. Sci. 2019, 1, 1-14. [CrossRef]

27. Volna, E. Introduction to Soft Computing, 1st ed.; Dept. of Computer Science University of Ostrava: Ostrava, Czechia, 2013 ; p. 137.

28. Sadrmomtazi, A.; Sobhani, J.; Mirgozar, M.A. Modeling Compressive Strength of Eps Lightweight Concrete Using Regression, Neural Network And Anfis. Constr. Build. Mater. 2013, 42, 205-216. [CrossRef]

29. Chandwani, V.; Agrawal, V.; Nagar, R. Modeling Slump of Ready Mix Concrete Using Genetic Algorithms Assisted Training of Artificial Neural Networks. Expert Syst. Appl. 2015, 42, 885-893. [CrossRef]

30. Alshihri, M.M.; Azmy, A.M.; El-Bisy, M.S. Neural Networks For Predicting Compressive Strength of Structural Light Weight Concrete. Constr. Build. Mater. 2009, 23, 2214-2219. [CrossRef]

31. Prasad, B.K.R.; Eskandari, H.; Reddy, B.V.V. Prediction of Compressive Strength of Scc And Hpc With High Volume Fly Ash Using ANN. Constr. Build. Mater. 2009, 23, 117-128. [CrossRef]

32. Diab, A.M.; Elyamany, H.E.; Abd Elmoaty, A.E.M.; Shalan, A.H. Prediction of Concrete Compressive Strength Due To Long Term Sulfate Attack Using Neural Network. Alex. Eng. J. 2014, 53, 627-642. [CrossRef]

33. Caglar, N.; Elmas, M.; Yaman, Z.D.; Saribiyik, M. Neural Networks In 3-Dimensional Dynamic Analysis of Reinforced Concrete Buildings. Constr. Build. Mater. 2008, 22, 788-800. [CrossRef]

34. Jenkins, W.M. A Neural Network For Structural Re-Analysis. Comput. Struct. 1999, 72, 687-698. [CrossRef]

35. Chang, C.C.; Chang, T.Y.P.; Xu, Y.G.; Wang, M.L. Structural Damage Detection Using An Iterative Neural Network. J. Intell. Mater. Syst. Struct. 2000, 11, 32-42. [CrossRef]

36. Kim, J.T.; Ryu, Y.S.; Cho, H.M.; Stubbs, N. Damage Identification In Beam-Type Structures: Frequency-Based Method Vs Mode-Shape-Based Method. Eng. Struct. 2003, 25, 57-67. [CrossRef]

37. Bakhary, N.; Hao, H.; Deeks, A.J. Damage Detection Using Artificial Neural Network With Consideration of Uncertainties. Eng. Struct. 2007, 29, 2806-2815. [CrossRef]

38. Sahoo, B.; Maity, D. Damage Assessment Of Structures Using Hybrid Neuro-Genetic Algorithm. Appl. Soft Comput. 2007, 7, 89-104. [CrossRef]

39. Günaydın, H.M.; Doğan, S.Z. A Neural Network Approach For Early Cost Estimation of Structural Systems of Buildings. Int. J. Proj. Manag. 2004, 22, 595-602. [CrossRef]

40. Nyarko, M.H.; Nyarko, E.K.; Moric, D. A Neural Network Based Modelling And Sensitivity Analysis of Damage Ratio Coefficient. Expert Syst. Appl. 2011, 38, 13405-13413. [CrossRef]

41. Hadi, M.N.S. Neural Networks Applications In Concrete Structures. Comput. Struct. 2003, 81, 373-381. [CrossRef]

42. Zapico, J.L.; Gonzalez, M.P. Numerical Simulation of A Method For Seismic Damage Identification In Buildings. Eng. Struct. 2006, 28, 255-263. [CrossRef]

43. Zhang, J.; Foschi, R.O. Performance-Based Design And Seismic Reliability Analysis Using Designed Experiments And Neural Networks. Probabilistic Eng. Mech. 2004, 19, 259-267. [CrossRef]

44. Gonzalez, M.P.; Zapico, J.L. Seismic Damage Identification In Buildings Using Neural Networks And Modal Data. Comput. Struct. 2008, 86, 416-426. [CrossRef] 
45. Cheng, J. Serviceability Reliability Analysis of Prestressed Concrete Bridges. Ksce J. Civ. Eng. 2013, 17, 415-425. [CrossRef]

46. Giordano, F.; Rocca, M.L.; Perna, C. Input Variable Selection in Neural Network Models. Commun. Stat. Theory Methods 2014, 43, 735-750. [CrossRef]

47. Hammer, B. Neural Networks; Elsevier: Amsterdam, The Netherlands, 2014; Volume 1, pp. 817-855.

48. Basheer, I.A.; Hajmeer, M. Artificial Neural Networks: Fundamentals, Computing, Design, And Application. J. Microbiol. Methods 2000, 43, 3-31. [CrossRef]

49. Castellano, G.; Fanelli, A.M. Variable Selection Using Neural-Network Models. Neurocomputing 2000, 31, 1-13. [CrossRef]

50. Beale, M.H.; Hagan, M.T.; Demuth, H.B. Neural Network Toolbox TM_User's Guide; The MathWorks, Inc.: Natick, MA, USA, 2015.

51. Krogh, A.; Vedelsby, J. Neural Network Ensembles, Cross Validation, and Active Learning. Adv. Neyral Inf. Process. Syst. 1995, 7, 21-238.

52. Utans, J.; Moody, J.; Rehfuss, S.; Siegelmannt, H. Input Variable Selection for Neural Networks: Application to Predicting the U.S. Business Cycle; IEEE Transactions on Knowledge and Data Engineering: New York, NY, USA, 1995; pp. 118-122.

53. Kotsovos, G.M.; Kotsovos, M.D. Flat slabs without shear reinforcement: Criteria for punching. Struct. Eng. 2010, 87, 1-8.

54. Kotsovos, G.M.; Kotsovos, M.D. A new approach to designing reinforcement to resist punching shear. Struct. Eng. 2010, 89, 20-25.

55. Pendharkar, U.; Chaudhary, S.; Nagpal, A.K. Neural network for bending moment in continuous composite beams considering cracking and time effects in concrete. Eng. Struct. 2007, 29, 2069-2079. [CrossRef]

56. Yang, K.H.; Ashour, A.F.; Song, J.K. Shear Capacity of Reinforced Concrete Beams Using Neural Network. Int. J. Concr. Struct. Mater. 2007, 1, 66-73.

57. Cladera, A.; Mari, A.R. Shear Design Procedure For Reinforced Normal And High-Strength Concrete Beams Using Artificial Neural Networks. Part I: Beams Without Stirrups. Eng. Struct. 2004, 26, 917-926. [CrossRef]

58. Cladera, A.; Mari, A.R. Shear Design Procedure For Reinforced Normal And High-Strength Concrete Beams Using Artificial Neural Networks. Part II: Beams With Stirrups. Eng. Struct. 2004, 26, 927-936. [CrossRef]

59. Wei, W.W.; Che, Y.; Gong, J.X. Shear Strength Prediction For Reinforced Concrete Beams Without Stirrups. Mag. Concr. Res. 2011, 63, 433-440. [CrossRef] 